\title{
The Origin and Content of Expletives: Evidence from "Selection"
}

\section{Citation}

Deal, Amy Rose. 2009. The origin and content of expletives: Evidence from "selection". Syntax 12(4): 285-323.

\section{Published Version}

doi:10.1111/j.1467-9612.2009.00127.x

\section{Permanent link}

http://nrs.harvard.edu/urn-3:HUL.InstRepos:4263738

\section{Terms of Use}

This article was downloaded from Harvard University's DASH repository, and is made available under the terms and conditions applicable to Other Posted Material, as set forth at http:// nrs.harvard.edu/urn-3:HUL.InstRepos:dash.current.terms-of-use\#LAA

\section{Share Your Story}

The Harvard community has made this article openly available.

Please share how this access benefits you. Submit a story.

\section{Accessibility}


The origin and content of expletives:

evidence from "selection"

Amy Rose Deal

Abstract. While expletive there has primarily been studied in the context of the existential construction, it has long been known that some but not all lexical verbs are compatible with there-insertion. This paper argues that there-insertion can be used to diagnose $v \mathrm{Ps}$ with no external argument, ruling out transitives, unergatives, and also inchoatives, which are argued to project an event argument on the edge of $v \mathrm{P}$. Based on the tight link between there-insertion and low functional structure, I build a case for low there-insertion, where the expletive is first merged in the specifier of a verbalizing head $v$. The low merge position is motivated by a stringently local relation that holds between there and its associate DP; this relation plays a crucial role in the interaction of there with raising verbs, where local agreement rules out cases of "too many theres" such as * There seemed there to be a man in the room. An account of these cases in terms of phase theory is explored, ultimately suggesting that there must be merged in a non-thematic phasal specifier position.

Keywords: there-insertion, inchoatives, economy, agreement, phase theory

\section{Introduction}

This paper is concerned with the English expletive there. The general subject of expletives needs no introduction; expletive constructions in the world's languages have motivated an unusually rich and extensive literature throughout the history of generative syntax. ${ }^{1}$ In the course of this history, substantial advances have been made in understanding what sorts of expletives are possible, and what expletives of particular types reveal about other features

\footnotetext{
* Thanks to Rajesh Bhatt, Kyle Johnson, Gary Milsark, audiences at the 2006 ECO5 workshop and 31st Penn Linguistics Colloquium, and the anonymous reviewers for much helpful commentary. This material is based upon work supported under a National Science Foundation Graduate Research Fellowship.

${ }^{1}$ For (standard) English especially, see the reference list provided by Levin (1993: 88), as well as Lasnik (1992, 1995), Williams (1994), Chomsky (1995, 2000, 2001), den Dikken (1995), Groat (1995), Rothstein (1995), Runner (1995: §8.2), Basilico (1997), Moro (1997), Frampton and Gutmann (1999), Law (1999), Richards (1999), Schütze (1999), Sabel (2000), Hale and Keyser (2000), Bobaljik (2002), Bošković (2002), Bowers (2002), Hazout (2004), Kuno and Takami (2004: ch 2), Sobin (2004), Richards and Biberauer (2005), Rezac (2006); on other languages and varieties of English see Thráinsson (1979), Platzack (1983), Travis (1984: ch. 5), Burzio (1986), Maling (1988), Demuth (1990), Vikner (1995), Bobaljik and Jonas (1996), Toribio (1996), Cardinaletti (1997), Moro (1997), Koster and Zwart (2000), Holmberg and Nikanne (2002), Taraldsen (2002), Vangsnes (2002), Sells (2005), Henry and Cottell (2007), among many many others.
} 
of particular languages. The present work focuses on there, one expletive in one language, in the hopes of contributing a detailed case study to the general question of expletive typology in the framework of Principles and Parameters, presently instantiated as the Minimalist Program (Chomsky 1995 et seq.).

In the course of this investigation, I examine two questions central to the analysis of there. The first is the problem of ORIGIN: where does there come from? Where is there base-generated, or externally Merged? The second question is the problem of CONTENT: what is there made of? What features does it comprise? To probe these two crucial mysteries, we will focus on a contrast which has been largely overlooked in the recent literature on there-constructions: the apparent "selection" of there by various predicates, as exemplified in (1) and (2) (verb lists excerpted from Levin 1993).

(1) a. There appeared a shadowy figure in the doorway.

b. There arrived a train in the station.

likewise: accumulate, coexist, emerge, hover, live, lurk, predominate, sit, swing

(2) a. *There laughed a man in the hallway.

b. *There melted a block of ice in the front yard.

c. *There slowed a train on the eastbound track.

likewise: abate, break, collect, detonate, divide, level, redden, solidify, vaporize

While this distinction between verb classes has been documented, e.g. in Levin's work, it has not been satisfactorily explained. ${ }^{2}$ I argue in the first part of this paper (sections 2-5) that there-insertion does not target predicates at random. Rather, it systematically separates out $v$ Ps with external arguments in their specifier position from those whose specifier position may remain empty. I argue that this division concerns not only the distinction between unergatives and unaccusatives, but also the distinction between "change of state" unaccusatives and plain unaccusatives. I formalize the difference between the two classes of unaccusatives in terms of the presence or absence of a CAUSE head, whose semantics introduce a bi-eventive LF and whose syntax requires an event argument in Spec, $v \mathrm{P}$. The sensitivity of there-insertion to this argument-structural distinction provides compelling evidence for a "low origin" account, where there is base-generated in the specifier of the verbalizing head $v$.

In the second half of the paper (sections 6-8), I turn to the question of why there should be inserted low, arguing that its low base position is motivated by very strong locality restrictions that hold between there and its "associate" nominal (a shadowy figure in (1a), a train in (1b)). This finding motivates a turn toward the problem of content; in particular, the locality required to hold between there and its associate suggests an Agree relation in terms of some feature(s) borne by there. The Agree relation is constrained by phase boundaries (Chomsky 2000, 2001), such that there must originate on the edge of a

\footnotetext{
2 Previous discussions include Burzio's (1986: §2.7.3), which singled out the class of unaccusatives (ergatives in his terminology) as well as unergatives with heavy NP-shifted subjects; Freeze's (1992), which required a subcategorized locative argument; Haegeman's (1991) and Hale and Keyser's (2000), which posited a link between there-insertion and causative alternations; and Kuno and Takami's (2004), which posits a functionally-based filter on there-insertion. On the Haegeman/Hale and Keyser theory see section 3.3 and footnote 21. See also Szabolcsi (1986) on Hungarian verbs showing a definiteness effect, and Maling (1988) on related issues in Swedish.
} 
phase in order to agree with a phase-internal associate. When the associate remains in its base position inside vP, there must originate on the edge of the vP phase. Should the associate move out of the $v \mathrm{P}$ phase, however, in particular due to (what has been termed) heavy NP shift, there may originate higher in the structure than $v \mathrm{P}$, provided it finds an appropriate phase head in whose (non-thematic) specifier to lodge. A consideration of the consequences of this final type of construction for the grammar of expletives concludes our investigation.

\section{The problem of origin}

A long tradition in generative syntax has taken expletives to originate "upstairs": the subject position, daughter to S, or Spec,TP (e.g. Emonds 1970, Milsark 1974, Stowell 1978, Burzio 1986, among many others). Other subjects were repositioned downstairs into VP (Koopman and Sportiche 1991, i.a.), then slightly up into a functional projection VoiceP or $v$ P (Kratzer 1996), but expletives stayed upstairs in Spec,TP. . This "high origin" account of expletives is continued in such work as Lasnik (1995) and Chomsky (1995, 2000, 2001), and remains the default assumption in Minimalist theory. In this section, I briefly review the issues for a theory of high origin, before turning to a discussion of factors constraining an alternative, low-origin account.

Chomsky's (2000) analysis posits that there is freely Merged into Spec,TP in order to fulfill the requirement that this head have a specifier (an EPP feature). There is a nominal, but a deficient one; as a result of its deficiency, it does not participate in Casechecking relations. Thus, whenever there is inserted in Spec,TP, the nominative Case assigned by $\mathrm{T}$ (and accompanying agreement features) must target some other nominal in the clause. Chomsky posits that this Case is assigned by the operation Agree to the associate of there.

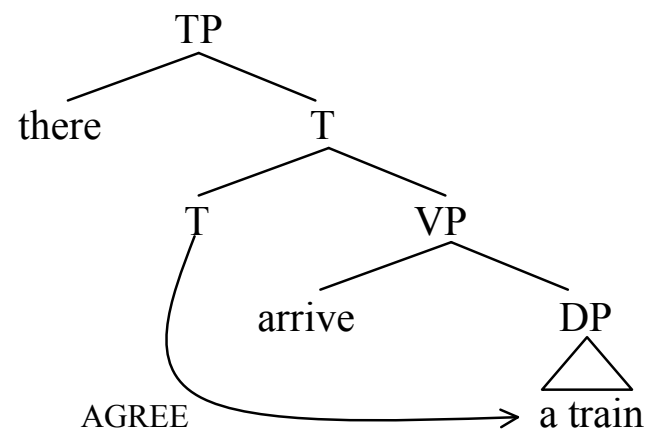

That the Agree relation must target some accessible nominal automatically rules out there with argumentless weather verbs like rain, as well as with prepositional-object verbs.

(4) a. *There rained.

b. *There fell down the stairs.

\footnotetext{
${ }^{3}$ Exceptions include Moro (1997) (and previous versions circulating much earlier), Hoekstra and Mulder (1990), den Dikken (1995), Basilico (1997), Hale and Keyser (2000), Sabel (2000), Bowers (2002), Hazout (2004), Nomura (2004), Richards and Biberauer (2005), Richards (2007).
} 
However, it is not at all clear how the theory rules out cases which seem to differ from (3) only with respect to the content of the $\mathrm{V}$ head, e.g. *There slowed a train (on the eastbound track), (5).

(5)

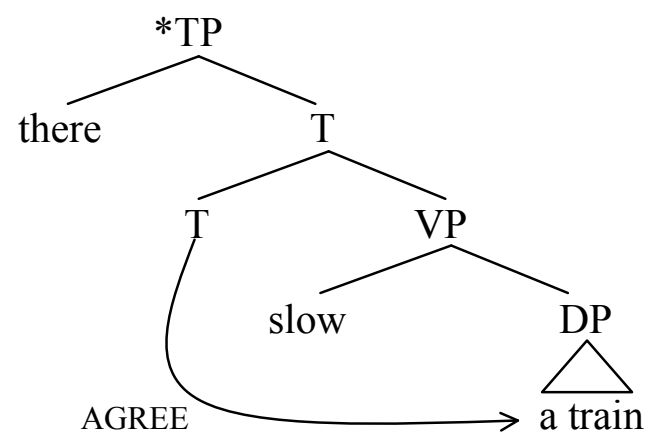

In essence, two factors must fall into line for there-insertion to occur in Chomsky's (2000) framework. First, T must have an EPP feature which (prior to there-insertion) is unchecked. Second, there must be a non-Case marked nominal within an appropriately local domain in order for $\mathrm{T}$ to discharge its Case feature via Agree. Thus, so long as a verb may combine with finite $\mathrm{T}$ and introduce a nominal which is not independently Casemarked, there-insertion is predicted to be possible. Verbal semantics plays no role; the functional heads in which verbs are (in some frameworks) encased play no role. In this way, the high origin account comes to massively overgenerate there clauses, as demonstrated by (5). ${ }^{4}$

It should be noted that these problems for the Chomsky (2000) theory are problems specifically for the high origin aspect of the proposal. Importantly, the overgeneration of cases like *There slowed a train does not in itself show that the operation Agree should be discarded, or that Case should not be assigned to the associate. Rather, holding other assumptions constant, the grammaticality of simple cases like (6) shows that Agreement and Case-assignment must be possible in structures like (5).

A train slowed (on the eastbound track).

Here, the Agree-based framework requires that T enters into a relationship with the DP $a$ train. As a result of this relationship, a train receives nominative Case. Furthermore, to satisfy EPP on T, the Agree relation between $\mathrm{T}$ and $a$ train forces the latter to move to Spec, TP.

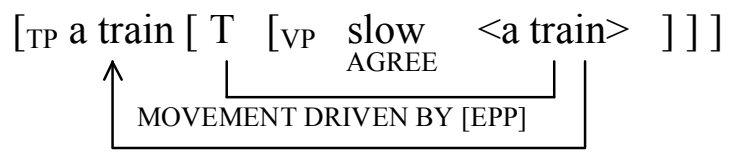

\footnotetext{
${ }^{4}$ The high origin account overgenerates even in cases where another Case-marker is available in the clause. In such circumstances, we predict transitive expletive constructions to be possible:

(i) [те There $\underline{\mathrm{T}}\left[{ }_{\mathrm{vр}}\right.$ a man $\underline{v}[\mathrm{vp}$ eat an apple $\left.\left.]\right]\right]$

Here two Case-assigners, $\mathrm{T}$ and $v$, are paired with two arguments, $a$ man and an apple. See section 4 for a low-origin explanation of the restrictions on transitive expletives in English; see also note 35.
} 
In terms of Case-assignment and Agreement, this example is exactly the same as the ungrammatical (5); only the problematic high expletive has been removed.

Turning away from the high origin proposal opens up the immediate question of exactly where there is base-generated. An appealingly simple position would be that there is selected for by particular V heads. However, there are several concerns raised by such an approach. First, such selection would have to be always merely optional, except perhaps in the case of the existential copula. Second is the issue of selecting an element which appears to be devoid of intrinsic meaning, as noted by Lasnik (1995). The third problem comes not from the apparent vacuity of there, but from the fact that it is an external argument, structurally speaking (i.e., it occupies the same position as external arguments). A line of research stemming from work by Marantz (1984) and Kratzer (1996) has suggested that selection for external arguments is in general problematic, as such arguments do not seem to be true arguments of the $\mathrm{V}$ head. A final problem is that some verbs allow thereinsertion contingent on the position of the associate:

(8) a. *Suddenly there walked a unicorn into the room. ${ }^{5}$

(Milsark 1974:246)

b. Suddenly there walked into the room a unicorn.

On a selection account, such facts would force the selectional properties of the verb to be dependent on the surface syntactic position of its nominal argument, an unwelcome complication. (We return to these contrasts in section 8.)

If there is not freely merged in Spec, TP, and not selected by particular $\mathrm{V}$ heads, what controls its distribution? In the coming sections, I argue that it is the functional structure surrounding verb roots which controls the insertion of there. In particular, in standard cases, there can only be inserted on edge of a $v \mathrm{P}$ that lacks an external DP or event argument (i.e., into a non-thematic $v \mathrm{P}$ specifier position).

\section{$3 \quad$ There-insertion and the structure of causatives}

Levin (1993) presents a listing of verb classes that do and don't allow there-insertion. Among the verbs that do take there, we have seen appear and arrive; among those that don't take there, we have seen laugh, melt and slow. What is it about these verbs that determines their compatibility with there-insertion?

The literature widely acknowledges the incompatibility of there-insertion with transitives as well as unergatives, verb classes known to require external arguments of $v \mathrm{P}{ }^{6}$ This leaves only unaccusatives; however, as melt and slow show, not all unaccusatives are admissible with there-insertion. Rather, as Levin (1993) points out, only those unaccusatives which do not denote a "change of state" may appear with there. Integrating

\footnotetext{
5 Examples of this type are marked as grammatical in Hoekstra and Mulder (1990) and Belvin and den Dikken (1997). However, I have found no speaker who accepts them, and they are acknowledged to be ungrammatical by Milsark (1974), Lumsden (1988: 39) and others.

${ }^{6}$ There are exceptions to the ban on there-insertion with unergatives; see Burzio (1986: 162), Kuno and Takami (2004: ch 2). There-sentences with unergative verbs are taken up below in the discussion of two factors that can license them: the progressive (section 5) and outside verbals (section 8).
} 
Levin's generalization into the wider picture, we arrive at the generalization in (9), equivalently stated as in (9'):

There-insertion is incompatible with

a. transitives

b. unergatives (Burzio 1986, §2.7.3; Haegeman 1991)

c. "change of state" verbs (Levin 1993)

(9') There-insertion is compatible only with unaccusatives that are not "change of state" verbs

In order to formalize the generalization in (9'), a definition of the heretofore scarequoted category of change of state verbs will be required. It is clear that the most intuitive classification will not be empirically adequate. On the one hand we find predicates like disappear, which do not seem to denote changes of state, and yet reject there-insertion; ${ }^{7}$ on the other we encounter verbs like bloom, which seem to fall into the change-of-state category and yet can allow there-insertion. Turning to formal properties, we learn from Jackendoff (1996), Hay, Kennedy and Levin (1999), Levin \& Rappaport Hovav (2002) and others that the change of state class does not coincide with an aspectual category (e.g. achievements; cf. Dowty 1979). What then could be the defining property of the change of state verbs, the unaccusatives that do not allow there?

I argue that Levin's change of state verbs are those whose intransitive form occurs in $v \mathrm{P}$ with a causative head CAUSE. In accordance with (9'), verbal structures which contain this head do not support there-insertion. The causative hypothesis may be formulated as follows:

(10) Causative hypothesis. The $v \mathrm{P}$ of an unaccusative verbal root may contain expletive there just in case it does not contain CAUSE.

The proper representation of change-of-state, inchoative or anticausative intransitive verbs has been the subject of a long debate in the literature to which I cannot do real justice here (see for instance Dowty 1979, Levin and Rappaport Hovav 1995, Pesetsky 1995, Wunderlich 1997, Piñón 2001, Reinhart 2002, Alexiadou and Anagnostopoulou 2004, Alexiadou et al. 2005, 2006, Kallulli 2006, Koontz-Garboden 2007). Nonetheless, certain aspects of the problem of there-insertion and the change-of-

\footnotetext{
${ }^{7}$ This is not to deny that there are ever grammatical there-sentences with disappear; however, these are outside verbals, where the associate has left its base position:

(i) Sometime during this last pluvial there disappeared from Africa the last manlike rivals of man as we know him. (http://oneworldmagazine.org/focus/etiopia/lost1.html)

(ii) There disappeared from the safe two diamond rings that her ex-husband had given her (Kuno and Takami 2004: 55)

Outside verbals do not obey the definiteness restriction (Milsark 1974), and so the absence of definiteness effects in (iii), from Lumsden (1988: 237), may suggest that this case is an outside verbal, too (with the final PP extraposed from VP). See section 8 for an analysis.

(iii) One by one during the day the vessels left until finally there disappeared our own ship over the horizon.
} 
state generalization (9') shed light on some of the issues at stake, supporting the formalization at play in (10).

First, generalization (9') requires us to find some way to distinguish change-ofstate unaccusatives from other unaccusatives. We cannot adopt any analysis according to which change-of-state verbs are formally identical to other unaccusatives (e.g. arrive, hang). The problem of there-insertion also places a requirement on how the differences among unaccusatives are to be encoded in the grammar. I take it that there-insertion is as good an example as any of a phenomenon that occurs in the syntax, not the lexicon; therefore, in order to allow generalizations about there-insertion to be stated in a way that avoids reference in the syntax to the internal structure of lexical items (i.e. preserving lexical integrity), we set aside views that posit a difference between change-of-state unaccusatives and unaccusatives like arrive and hang only in the lexicon or in "event structure" (e.g. Levin and Rappaport Hovav 1995, Wunderlich 1997, Koontz-Garboden 2007). Finally, my proposal can be contrasted with work that posits an operator in the syntax for change of state intransitives, but identifies this head not as CAUSE but as BECOME (e.g. Alexiadou and Anagnostopoulou 2004). The reasons for this will become clear as we discuss the diagnostics for causal semantics in intransitive verbs, which rely on a bi-eventive structure that is contributed by CAUSE but not by BECOME. ${ }^{8}$

As argued below, the motivations for CAUSE as an element of $v \mathrm{P}$ projection are unrelated to there-insertion, and thus the correlation between there-insertion and the diagnostics for CAUSE is particularly striking. On the proposal adopted here, what appears to be a lexical semantic distinction among verbs can be reduced to a syntactic distinction between different types of structures in which verbal roots can occur. It is this structural distinction to which there-insertion is sensitive.

The semantics of the CAUSE head can be given as follows, following Pylkkänen (2002), Kratzer (2005) (where $s$ is the type of eventualities and $t$ the type of propositions):

$$
\text { CAUSE: } \quad \lambda \mathrm{P}_{<\mathrm{s}, \mathrm{t}>} \lambda \mathrm{e} \exists \mathrm{e}^{\prime} . \mathrm{P}\left(\mathrm{e}^{\prime}\right) \& \text { direct-cause }(\mathrm{e})\left(\mathrm{e}^{\prime}\right)
$$

Two aspects of this denotation are worth noting. First, the CAUSE head does not introduce a causer argument (an entity); rather, it introduces only a causing event. ${ }^{9}$ I will argue that the causing event is syntactically represented as an external argument of $v \mathrm{P}$ (correspondingly proposing a slight modification to (11)). Secondly, the relation of causation involved in the CAUSE head is crucially one of direct causation; the causal chain between the two events is constrained to rule out intervening causes (Kratzer

\footnotetext{
${ }^{8}$ A bi-eventive BECOME operator is considered (but not adopted) by Parsons (1990: 119), and proposed by Piñón (2001). For Parsons the second event in addition to the resultant state is the change of state itself, whereas for Piñón this second event $e$ is that which "an object $x$ comes to be in a state ... by virtue of." Piñón's bi-eventive inchoative operator seems to me compatible with an analysis in terms of causation between the result state and $e$.

9 This conception of causation as relating pairs of events follows Parsons (1990), Piñón (2001), Pylkkänen (2002) and Kratzer (2005), and is "the standard view" among philosophers according to Schaffer (2007). It can be contrasted with views of causation that take it to be a relation between entities (individuals) and events (at least in cases where the subject is not overtly event-denoting), such as those advanced by Jackendoff $(1976,1983)$ and Wunderlich (1997), as well as with views that take causation to be a relation between events but include with the CAUSE head a necessary place for a causer argument, as in Levin and Rappaport Hovav (1995) and Pylkkänen (2002), the former generally and the latter only for English.
} 
2005). ${ }^{10}$ In virtue of the directness of the causation, the CAUSE head in effect subsumes the effect sometimes attributed to a BECOME operator in inchoatives (e.g. by Dowty 1979 and works following), viz the change of state. A state that already holds (or an event that is already ongoing) cannot be caused; if snow is already in a melted state, for instance, one cannot cause it to melt. ${ }^{11}$ Thus, given that the CAUSE head introduces an event $s^{\prime}$ that is the direct cause of the state/event $s$ denoted by the verb root, it necessarily refers to the beginning of $s$ and to the theme of $s$ entering into $s$. This is the change of state meaning.

The following sections outline evidence from prepositional modifiers, eventive/stative contrasts and causative alternations in support of the Causative Hypothesis (10). In each case, those structures passing tests for the bi-eventive structure of the CAUSE head disallow there-insertion, while structures with there-insertion fail tests for the CAUSE head.

\subsection{Prepositional modifiers}

For the reasons outlined above, I take the hallmark of change-of-state verbs to be the inclusion of CAUSE in the verbal projection. ${ }^{12}$ Because CAUSE contributes causative meaning by introducing a causing event, causative structures are bi-eventive. A major source of evidence for the presence of a bi-eventive structure in certain intransitive $v$ Ps comes from PP modifiers which, in a number of languages, can specify the causing event. In English, German and Greek, for example, the causing event of inchoatives can be referenced by by itself or by a PP headed by a preposition like from (Chierchia 1989, DeLancey 1984, Levin and Rappaport Hovav 1995, Alexiadou et al. 2005, 2006): ${ }^{13}$

(12)a. The window cracked from the pressure

b. The window cracked by itself (without outside help)

(13)a. Die Vase zerbrach durch ein Erdbeben The vase broke through an earthquake.

\footnotetext{
${ }^{10}$ Alternative conceptions of direct causation are presented by Dowty (1979: 98), Lewis (1986: 184-188) and by Wunderlich (1997: 37). Of these, only Lewis' analysis is compatible with the view that causation holds between events, not individuals and events.

${ }^{11}$ It has been noted that inchoatives may be used in certain cases where the state does hold previously to any change; an object may redden even if it is already red. This is a problem for a strict Dowty-style treatment of BECOME (cf. Dowty 1979: 140), which allows BECOME $p$ to be true at an interval $I$ just in case $p$ is not true at an interval $J$ containing the initial bound of $I$. Dispensing with BECOME in favor of mere causation may save us some trouble here. If a particular eventuality $e$ is caused by another event $e$, $e$ could not have held prior to $e^{\prime}$, though what exactly was the case prior to $e$ ' is left open. Just because we are describing $e$ as a state of redness, for instance, we need not conclude that $e$ followed a state devoid of redness.

12 I do not assume any necessary connection between inchoativity and participation in the causative alternation; see section 3.3.

${ }^{13}$ There are well-known restrictions on the causal readings of from-PPs, most notably that they must name a causing event, not an agent or instrument (Alexiadou et al. 2005, 2006, Kallulli 2006). This translates into an animacy restriction, since events are never animate. It appears that there are other restrictions on causal from as well; while verbs like crack or break accept it, verbs like disappear do not, despite the independent evidence for a causal analysis of disappear (see below). The precise constraints on causal from call for further research. What appears clear at present is that structures allowing causal from pass other tests for CAUSE, such as the by itself test; thus, causal readings of from imply the presence of CAUSE, although the lack of such readings does not imply the absence of CAUSE.
} 
b. Die Vase zerbrach von selbst

The vase broke by itself

(14)a. I porta espase apo to apotomo klisimo Greek; Alexiadou et al. 2005

The door broke by the abrupt closing

b. I porta anikse apo moni tis

The door opened by alone-SG hers

'The door opened by itself'

Of particular importance is the contrast with non-inchoative unaccusatives (i.e. unaccusatives without CAUSE) like arrive, a verb which readily allows there-insertion. When modifying arrive, by itself means only 'alone' and not 'without outside help'; a from-PP, likewise, may only specify a source and not a cause.

The student arrived early by herself

$\checkmark$ No one else arrived early. ('alone' reading)

* Nothing caused the early arrival. ('without outside help' reading)

The plane arrived from Tokyo/*from the tailwind.

The modificational facts support the view that inchoative $v$ Ps introduce a causing event which non-inchoative unaccusative vPs are devoid of. ${ }^{14}$ The postulation of a CAUSE head allows us to capture this bi-eventive structure in a compositional way.

The contrast between inchoatives like open or melt and non-inchoative unaccusatives like arrive correlates as predicted with the possibility of there-insertion: inchoative vPs cannot take there, whereas non-inchoatives may. Rephrasing in terms of our CAUSE diagnostics, whenever by itself or from can refer to the causing event, there-insertion is unavailable. Some examples are given in (17) below for inchoatives and in (15-16) above and (18) below for non-inchoative unaccusatives.

(17) Inchoatives; *there-insertion

a. melt

i. The ice cream melted by itself

$\checkmark$ alone reading

$\checkmark$ without outside help reading

ii. The ice cream melted from the heat (cause)

iii. *There melted some ice cream in the heat

b. disappear

i. The wizard disappeared by himself ${ }^{15}$

\footnotetext{
${ }^{14}$ The alternative to this view is to claim that by itself and from-PPs themselves introduce the causing event. There are two negative consequences of such a view. The first is that we must stipulate that causationintroducing modifiers cannot combine with certain verbs, e.g. arrive (though periphrastic expressions of causation with due to or because of are possible, showing the issue is not merely due to encyclopedic information about arrival). This makes it mysterious why only such verbs can take there. The second is that we must postulate two unrelated mechanisms for introducing causation: one for transitive clauses like The pressure cracked the window, and another for intransitives with PPs like The window cracked from the pressure (see Solstad 2006 for German durch).
} 


\begin{abstract}
$\checkmark$ alone reading
$\checkmark$ without outside help reading

ii. The wizard disappeared from fear (cause)

iii. *There disappeared a thief into the night
\end{abstract}

(18) Non-inchoative; there-insertion: hang

i. The portrait hung on the wall by itself

$\checkmark$ alone reading

* without outside help reading

ii. The portrait hung from the thumbtack/*the stapling $\quad$ (source, *cause) ${ }^{16}$

iii. There hung a portrait on the wall

We see in these examples the negative correlation between there-insertion and causative semantics for an unaccusative verb.

\title{
3.2 Eventive/stative contrasts
}

Certain verbs, for instance grow and bloom, show both stative and change-of-state behavior. Thus a sentence like The rosebush bloomed can mean either that the plant was in a floral state, or that it entered that state. The Causative Hypothesis (10) allows us to capture this contrast in virtue of its reference to structure, not the lexical content of a verb (word).

Milsark (1974: 250) noted that verbs like grow have two readings, only one of which is compatible with there-insertion. ${ }^{17}$ On their stative readings, such verbs allow there-insertion, but their eventive readings are not possible with there. ${ }^{18} 19$

(19)a. There grew some corn in our garden last year.

[stative; $\checkmark$ there]

b. *There grew some corn very slowly in Massachusetts.

[eventive; *there]

\footnotetext{
15 A reviewer suggests that the 'without outside help' reading of by itself, found with disappear, may extend to appear, a verb that allows there-insertion, for instance in the following context:

(i) Even though my grandmother used a walker, she still appeared at the police station by herself.

I find all by herself necessary to obtain this reading, a modification that may bear on the by itself diagnostic and is not necessary with disappear in (17b).

${ }^{16}$ The missing causative reading of the from-phrase can be found in The portrait hung due to/because of the stapling.

${ }^{17}$ He also notes verbs like follow, which like bloom and grow vary in allowing there-insertion, but unlike them lack change-of-state readings:
(i) a. A rainstorm followed.
(ii) a. A taxicab followed slowly.
b. There followed a rainstorm.
b. *There followed a taxicab slowly.

Following Burzio (1986: 160) and Lumsden (1988: 37-38), I analyze this alternation in terms of unaccusativity: follow is unaccusative in (i) and unergative in (ii). (Hide may be analyzed similarly.) Accordingly, translations of the two follows use different auxiliaries in Italian, and agentive nominal follower is appropriate for a taxicab but not a rainstorm.

${ }^{18}$ (19a) is from Milsark (1974: 250, ex 14), and (19b) is based on Milsark (250, ex 11a).

${ }^{19}$ Levin and Rappaport Hovav (1995: 161) suggest on the basis of evidence from Dutch that non-change of state bloom is unergative. (20a) suggests that the Dutch analysis is not applicable; English stative bloom is indeed unaccusative, just like change-of-state bloom. They differ in the presence of a CAUSE head.
} 
(20)a. There bloomed a rosebush on the patio.

b. *There bloomed a rosebush very slowly on the patio.

[stative; $\checkmark$ there]

[eventive; *there]

On the approach pursued here, we can make sense of this pattern in terms of the semantic contributions of verb root and CAUSE head. The verb root $\sqrt{ }$ BLOOM denotes a stative eventuality, viz the state of having flowers. If a CAUSE head is added, the resulting $v \mathrm{P}$ has an eventive, change of state meaning. In accordance with the causative hypothesis, thereinsertion is not sensitive to verb roots themselves; it is sensitive to the structures projected around them. ${ }^{20}$ For this reason we should not assume that a particular (unaccusative) verb will always permit/bar there-insertion, unless it consistently forbids/requires a CAUSE head. If the root $\sqrt{ }$ BLOOM can be used in the structure of the "pure unaccusative", i.e. without CAUSE, there-insertion should be possible. It is also in this configuration that we predict the stative semantics of the root to remain visible. There is no CAUSE head to introduce an eventive eventuality, just as there is no CAUSE head to interfere with thereinsertion. The major difference between intransitive bloom and an intransitive like hang seems to be that while both can appear in the pure unaccusative structure, wherein they remain stative and allow there-insertion, only bloom additionally allows the inchoative structure wherein CAUSE brings in both eventivity and a ban on there-insertion.

\subsection{Causative alternations}

On top of the evidence from causative-modifying by itself and from-PPs and eventivestative contrasts, causative alternations present confirming data in support of the Causative Hypothesis (10): in large part, verbs which participate in causative alternations cannot undergo there-insertion. ${ }^{21}$

It is widely agreed that a causative transitive verb is one which contains both an agent and an encoding of causation, e.g. break $k_{T R}$ or $h^{2} g_{T R}$ but not greet (agentive, but not causative) or hear (neither agentive nor causative). What is less widely agreed upon is the syntactic and semantic status of the intransitive forms of verbs like break and hang. The empirical sources of this disagreement become clear upon application of the CAUSE diagnostics given above to the set of intransitive verbs that have causative "alternants". There is no unified class of anticausative verbs as defined by the causative alternation. Participation in the causative alternation is not entirely predictable from the structure of an intransitive form. Verbs like hang or develop are non-inchoative (i.e. lack CAUSE) in their intransitive form but have a causative alternant (i.e. a form with CAUSE and the agentintroducing head Voice), whereas fall is inchoative in its intransitive form but does not

\footnotetext{
${ }^{20} \mathrm{Cf}$ Hoekstra and Mulder (1990: §3.2), who posit that "unergative verbs" can undergo there-insertion just in case their syntax is actually unaccusative.

${ }^{21}$ A similar generalization is expressed by Haegeman (1991: 307-312) and Hale and Keyser (2000): thereinsertion verbs cannot transitivize, in contrast to what Hale and Keyser call 'pure' unaccusatives and what Haegeman calls ergatives (in contrast to unaccusatives). Related analyses can be found in Levin and Rappaport Hovav (1995: ch 3). Incidentally, exactly the opposite generalization is proposed by Burzio (1986: 161) on the basis of unaccusatives like assemble, circulate and roll that allow there-insertion and have a transitive form; verbs like start are put aside (fn. 74). This kind of disagreement about the proper role of causative alternations in the analysis of there-insertion is to be expected so long as alternations remain the primary source of evidence for the presence of CAUSE in an intransitive form.
} 
alternate. This difference between hang and fall, by comparison to alternating inchoatives like break, is reflected in the possible structures for each verb root: ${ }^{22}$

(21)

\begin{tabular}{|c|c|c|}
\hline break & {$[$ CAUSE $[\sqrt{ }$ BREAK DP $]]$} & [DP [Voice [ CAUSE [VBREAK DP ]]]] \\
\hline fall & [ CAUSE [VFALL DP ]] & -- \\
\hline hang & {$[\mathrm{v}[\sqrt{ }$ HANG DP $]]$} & [ DP [ Voice [ CAUSE [VHANG DP ]]]] \\
\hline grow & $\begin{array}{l}{[\text { CAUSE }[\sqrt{\text { GROW DP }}]]} \\
{[\mathrm{v}[\sqrt{\text { GROW }} \mathrm{DP}]]}\end{array}$ & 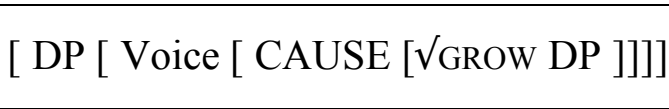 \\
\hline
\end{tabular}

We see in such data that so-called "causative-inchoative" alternations are in fact better labeled causative-unaccusative alternations, where the unaccusative form may be inchoative (break), non-inchoative (hang), or exist in both forms (grow). Given that the possibility of a transitive causative form does not strictly indicate the presence of a corresponding intransitive form with CAUSE, data from alternations should best be viewed only as a confirmation of the evidence from modifiers in determining which intransitive $v$ Ps contain CAUSE heads.

Keeping this variation in mind, we nonetheless find a pattern of some interest in the long-contested case of the verb disappear, which disallows there-insertion. We have seen above that evidence from modifiers supports an inchoative analysis of this verb; it appears that at least marginally, a causative alternant is also attested, (22a). ${ }^{23}$ By contrast, the morphologically related appear allows there-insertion and absolutely cannot be causativized, (22b).

(22)a. ?The magician disappeared a rabbit.

b. *The magician appeared a rabbit.

Here data from causative alternations dovetail with data from causation-modifiers and eventive-stative contrasts, as evidence converges on the Causative Hypothesis (10).

\section{Contexts for there-insertion}

We now have in hand a generalization about the verbs that do and don't take expletive there. In this section, I develop an account of there-insertion that aims to explain the pattern we have seen in terms of there-insertion in non-thematic specifiers of $v \mathrm{P}$. If an argument (nominal or eventive) must be projected in $\mathrm{Spec}, v \mathrm{P}$, there cannot be inserted; otherwise it is inserted freely into this position.

Following work by Marantz (1997) and others, I assume that verbal projections contain $v$ Ps whose heads are drawn from a closed class of "verbalizers", one member of

\footnotetext{
${ }^{22}$ I assume that paradigm gaps like the absence of transitive fall are encoded morphologically; see Harley and Noyer (2000). The underlying motivations for this morphological encoding may be related to conceptual issues of internal and external causation, as discussed by Levin and Rappaport Hovav (1995).

${ }^{23}$ The Oxford English Dictionary dates transitive disappear to 1897, providing the following attestation:

(i) We progressively disappear the faces of the dodecahedron. (Chem. News 19 Mar. 143)
} 
which is Kratzer's (1996) agent-introducing Voice head, (24). Unergative and transitive verbs occur in structures as follows: ${ }^{24}$

(23)a. Unergative

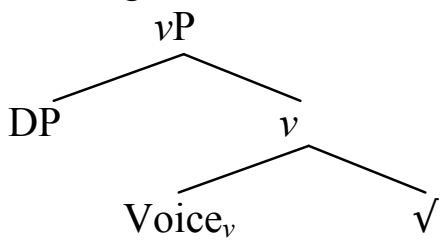

(24) b. Transitive

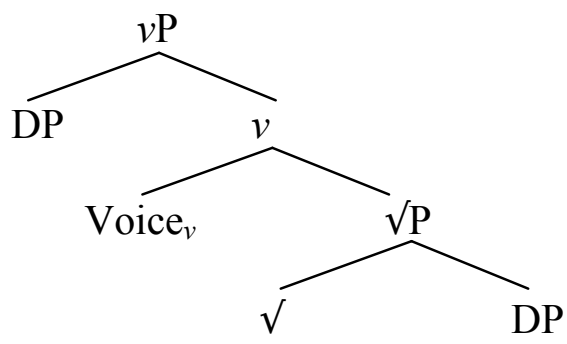

In both of these structures, the $v$ head requires an argument in its specifier position; there cannot be inserted (see also Bowers 2002: 195). Turning to unaccusatives, CAUSE as well may be considered a verbalizer; ${ }^{25}$ when CAUSE is not present in an unaccusative, a default verbalizer head $v_{\sim}$ is used. This gives us the structures in (25) for inchoative and "pure" unaccusatives (e.g. fall and arrive respectively):

(25) a. Inchoative

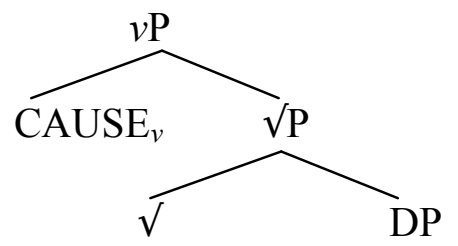

b. Non-inchoative unaccusative

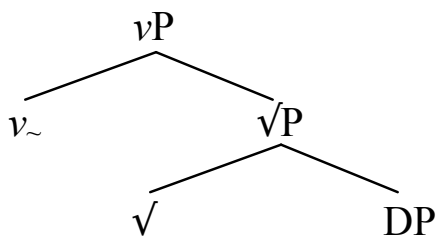

These four structures provide the distinctions crucial for the formalization of low there-insertion. In each case, if a verbalizing head requires an argument in its specifier position, there cannot be inserted. For structures containing Voice, the need for an argument is already encoded by the semantics in (24). We revise the denotation considered for CAUSE in (11) above to encode that with CAUSE as well as with Voice, an external argument in Spec, $v \mathrm{P}$ is required: in this case, the causing event. (26) gives the revised denotation for CAUSE, and (26b) exemplifies the proposed structure. ${ }^{26}$

$$
\text { a. } \quad \lambda \mathrm{P} \lambda \mathrm{e}^{\prime} \lambda \mathrm{e} \cdot \mathrm{P}(\mathrm{e}) \& \text { direct-cause }\left(\mathrm{e}^{\prime}\right)(\mathrm{e})
$$

\footnotetext{
${ }^{24}$ Unergative structure (23a) contains an agentive Voice head, as defined in (24), and thus represents only agentive intransitives. A similar structure is proposed for intransitives with external arguments receiving theta-roles other than agent (e.g. for cough, sleep), making appropriate changes to the argument-introducing $v$ head. Transitive structure (23b) does not contain CAUSE and thus represents only non-causative transitives, e.g. meet, kiss. Causative transitives such as break, kill and open are represented as [voicep Voice [CauseP CAUSE $\sqrt{ } \mathrm{P}]$, as in (21) (Alexiadou et al. 2005, 2006, Harley 2007). In both types of transitives, the argument of Voice (the agent) must appear in the thematic $v \mathrm{P}$ specifier position.

${ }^{25}$ See Koontz-Garboden $(2005,2007)$ on the link between change-of-state semantics and verbhood.

${ }^{26}$ Alternatively, we could retain the semantics for CAUSE given in (11) and place an event pronoun in the Spec, $\nu \mathrm{P}$ position if we could assume that the event pronoun would immediately be bound by lambda abstraction.
} 
b. Severing the causing event from its CAUSE head

$\lambda \mathrm{e}$. broken(the window)(e) \& direct-cause(s)(e)

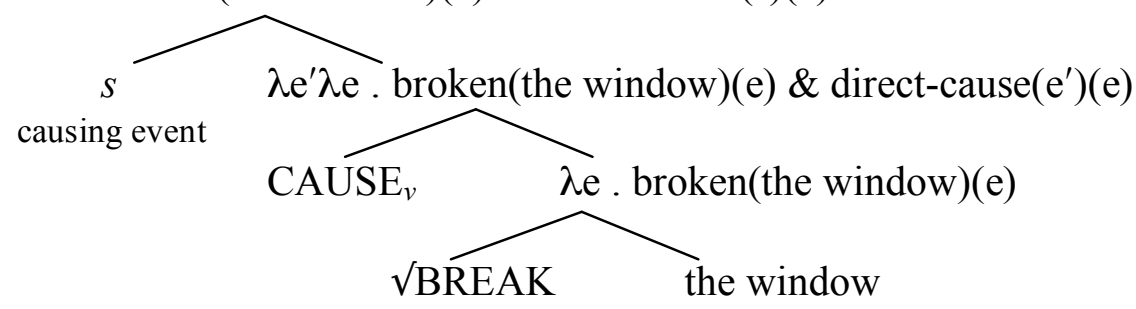

The reason why inchoative $v$ Ps cannot host there-insertion is then the same as the reason why agentive $v$ Ps cannot do so: for semantic reasons, the specifier of the verbalizer cannot remain empty.

For the final verbalizer, $v_{\sim}$, no such considerations apply. Since the verbalizing head fails to introduce an argument of either an eventive or an entity type, its specifier is non-thematic, and entirely free to accommodate there. It is thus through a process of interpretive elimination that there-insertion comes to be possible only in the specifier of non-inchoative unaccusatives.

\section{The special status of there be}

The discussion to this point has focused entirely on there-insertion independent of the copula -- so-called "presentational there" (Milsark 1974, Aissen 1975, Burzio 1986, Ward and Birner 1996, i.a.). ${ }^{27}$ Nevertheless, the framework laid out in the previous section gives us the tools necessary to account for why the copula in its many forms is invariably capable of bringing in there-insertion -- in passives (27), progressives (28), ${ }^{28}$ and existentials (29).

(27)a. There were several people arrested over the weekend.

b. There are thousands of healthy animals euthanized every day.

(28)a. There was a child loudly singing in the campground.

b. There are fans gathering outside the stadium.

(29)a. There will be a unicorn in the garden at $8 \mathrm{pm}$.

\footnotetext{
${ }^{27}$ This term is also sometimes used to describe cases of there-insertion with lexical verbs and V-PP-NP order, Milsark's outside verbals (Safir 1982:211, Schütze 1999). On V-PP-nominal order, see section 8.

${ }^{28}$ Word order data indicates that examples like (27) and (28) are not fully accounted for under an alternative, reduced relative analysis. Reduced relatives must precede full relatives, as shown in (i); but as (ii) shows, no such restriction appears in the there + progressive case. (Thanks to Rajesh Bhatt for bringing these data to my attention.)

(i) a. The teacher scolded [the student laughing in the hall who was wearing a Red Sox cap]

b. *The teacher scolded [the student who was wearing a Red Sox cap laughing in the hall]

(ii) a. There is a man laughing in the hall who's wearing a Red Sox cap.

b. There is a man who's wearing a Red Sox cap laughing in the hall.

See Rezac $(2006: 686,692)$ for a summary of evidence that passive and progressive expletive constructions cannot be analyzed only as reduced relatives, pace Law (1999) and other work.
} 
b. There is a problem with the coffeemaker.

To account for these cases, we might view the copula (in its many forms) as comprised of the dummy verbalizer $v_{\sim}$, embedding functional structure such as an Asp(ectual)P or a small clause. The presence of the dummy verbalizer in the progressive accounts for the contrast in (30): laugh cannot permit there-insertion, but be can. Insertion of there targets the specifier of $v_{\sim}$, though this need not be the only verbalizer in the overall structure.

(30)a. *There laughed a child in the hallway.

b. There is a child laughing in the hallway.

(31) A structure for (30b), There is a child laughing.

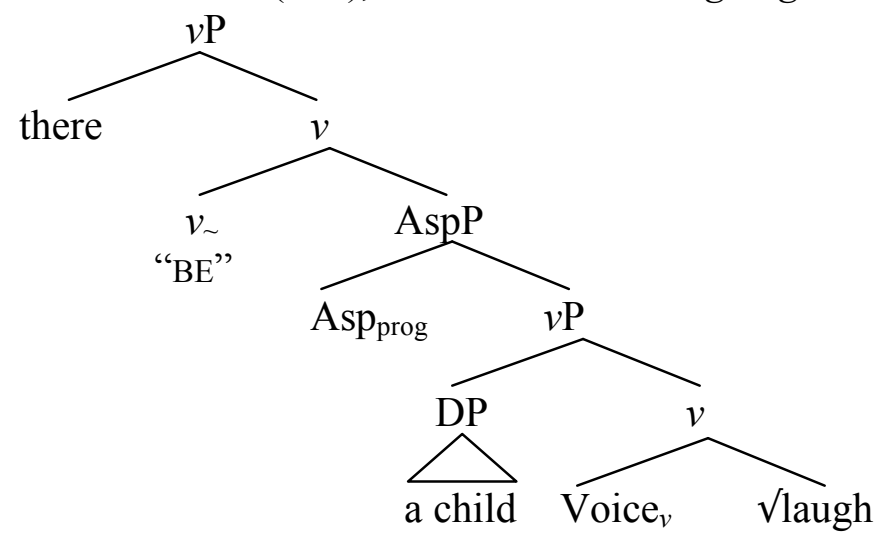

The same functional structure for the copula gives us existential sentences like (29). Here only one verbalizer is present, with its complement a small clause or a nominal; this sole verbalizer permits insertion of there.

\section{Agreement and the content of there}

Thus far I have argued for a low-generation solution to the problem of origin. This account makes sense of the distribution of there in terms of the heads that verbalize roots and structures of various sorts; only when a "pure" verbalizer is found in a syntactic structure will there-insertion be possible. The essence of this account is that there can be freely inserted in non-thematic Spec, $\nu \mathrm{P}$ positions. We turn now to the question of why it is $\mathrm{Spec}, \nu \mathrm{P}$ in particular that is targeted by there. It is this question which provides our segue to the problem of content.

Up to this point we have treated there as an element essentially visible only to the EPP feature of T. Presumably this means assigning it only what Chomsky (1995) has called a "D feature". In this section, I motivate a revision of the assumption that there is merely a D feature, ${ }^{29}$ on top of the D feature, it must contain uninterpretable features which are checked against its associate. The checking relation with the associate must be

\footnotetext{
${ }^{29}$ Or merely a number feature, as in Chomsky (1981), or merely a case feature, as in Travis (1984), or merely a person feature, as in Chomsky (2000: 125; 2001), etc.
} 
maximally local, and it is in order to satisfy this stringent locality that there can only be born in the specifier of a low phase head, Spec, $\nu \mathrm{P}^{30}$

\subsection{Too many theres}

Empirical motivation for an agreement relation between there and its associate comes from what I call the "too many theres" problem, references to which are scattered through the literature. Examples like (32), with multiple instances of there, are sharply ungrammatical:

(32)a. *There seemed there to be a man in the room.

b. *There seemed there to arrive a train in the station.

These examples are a problem for Chomsky's (2000) high-generation-of-there account, which predicts free Merger of there in each Spec,TP. They are just as much of a problem on the low origin account outlined above, which at present predicts the possibility of merger in Spec, $v \mathrm{P}$ of seem as well as in $\mathrm{Spec}, v \mathrm{P}$ of be or arrive.

(33) The too-many-theres problem

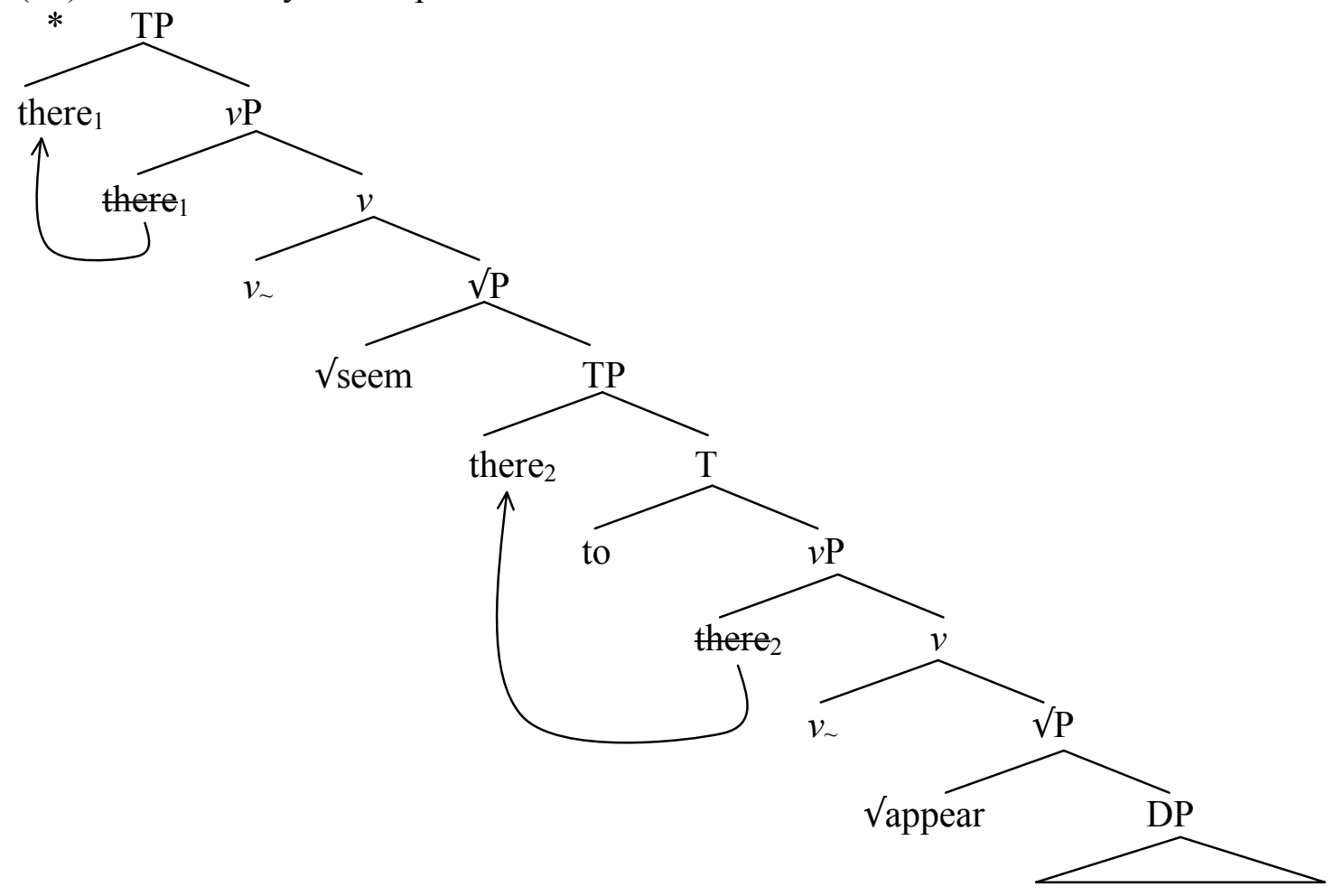

${ }^{30}$ If low origin is tightly linked to an agreement relationship with an associate, we might expect languages whose expletives are not generated low not to require any such relationship with a nominal. Icelandic $p a \delta$ provides initial support for this hypothesis. Platzack (1983) and Maling (1988) have argued that expletives in Icelandic always occupy Spec,CP. In contrast to a low expletive like there, pað is acceptable even with argument-less weather verbs, suggesting that no relationship with a DP is required.

(i) pað rignir

EXPL rains

The function of $p a \delta$-insertion in Spec,CP may be to preserve V2 order (Haiman 1974, Breckenridge 1975, but cf. Sells 2005 and references there); agreement with an associate does not seem to be necessary. 
a train in the station

The low origin account introduces a further puzzle of this type. Above, we saw that both unaccusatives and the progressive copula contain the $v_{\sim}$ verbalizer in whose specifier there may originate. However, we cannot insert there in both Spec, $v \mathrm{P}$ positions, (34).

*There is there arriving a train in the station.

The too-many-theres problem shows that free generation of there in any syntactic position (Spec,TP or Spec, $v \mathrm{P}$ ) must be constrained. Such examples will pose a problem for any theory on which (a) there does not get Case, or (b) there does not enjoy a close relationship with its associate.

While the literature provides ample precedent for the claim that there is Casemarked (with or without the help of the associate; see Chomsky 1986b, Hoekstra and Mulder 1990, Lasnik 1992, 1995, Groat 1995, Hazout 2004; cf. Cardinaletti 1997), let us explore instead the mileage we can get from abandoning the claim that there bears no relation to its apparent associate. The empirically sound generalization is that there-clauses of all stripes require a DP associate. The too-many-theres problem shows that a close relationship between there and verbs and their argument heads does not yield this for free. Let us then supplement the theory of there with the proposal in (35). ${ }^{31}$

\section{(35) Content}

There has uninterpretable features which it checks against its associate.

This is implemented as a local Agree relationship.

The account explored here is couched in the phase-based theory of locality (Chomsky 2000, 2001). In this framework, certain heads are designated as "phase heads"; when one of these phase heads is merged with its sister, the sister becomes impenetrable to further operations (i.e. is "spelled out"). Only the phase head and its specifier remain visible, the latter serving as an "escape hatch" for material which would otherwise be petrified inside the completed lower phase (see Chomsky 2000, 2001). (In what follows I show phase boundaries as falling between the specifier position and the phase head; for our purposes here they could equally well be drawn between the phase head and its sister, demarcating "spell out domains".) This framework thus derives two of the crucial properties of syntactic operations: locality and cyclicity.

A point of long-standing interest in generative work has been the exact definition of locality domains, which phases presently instantiate. ${ }^{32}$ Chomsky (2000) argued that the only phases are $\mathrm{C}$ and the head $v$ (here Voice) found in transitive argument-structure

\footnotetext{
${ }^{31}$ This proposal has empirical advantages over an alternative "big DP" account, according to which there and its associate originate within a single DP constituent from which there is subsequently extracted (Basilico 1997, Sabel 2000). While a big DP proposal can presumably account for the one-to-one relationship between theres and associates (assuming we can rule out "supersize DPs" containing a nominal and more than one there), it predicts that there should be compatible with all sorts of $\mathrm{vP}$ structures, contrary to fact.

${ }^{32}$ See Boeckx and Grohmann (2007) for a catalogue of similarities between phases and their predecessors in the Barriers model of Chomsky (1986a). The reader is invited to insert an alternative term for locality domains in the place of phase in the text. What will be crucial is that both movement and agreement relations must respect such domains.
} 
projections. However, work by Legate (2002) has suggested that all $v$ heads, including those found with passive and unaccusative verbs, pass diagnostics for phase-hood; in particular, they seem to provide intermediate landing sites for successive cyclic movement. We will see shortly that there-insertion provides further evidence for the existence of locality domains defined over all $v$ Ps, including those projected around unaccusatives.

To see this, let us first consider the case of (34), *There is there arriving a train in the station. We predict that there can be generated in the projection of the progressive copula, as well as in the projection of the unaccusative verb. Since there is permitted with an unaccusative independently of the progressive higher up, in a bottom-up syntactic model we cannot block the unaccusative $v_{\sim}$ from allowing there in this instance. Supposing that unaccusatives project impenetrable $v \mathrm{P}$ domains, let us suppose in addition that there must obey strict locality constraints in its agreement relation with its associate. In particular, the agreement relation is possible from the specifier of a phase-head into the sister of the phase-head, but it is not possible otherwise across phase boundaries. Then only the lower there in (36), which is generated in the specifier of the unaccusative $v$, will be sufficiently close to the associate to enter into an Agree relationship. The higher there, generated in the specifier of the progressive copula, will be too far away. ${ }^{33}$

(36) Unaccusative: higher there is too far from associate

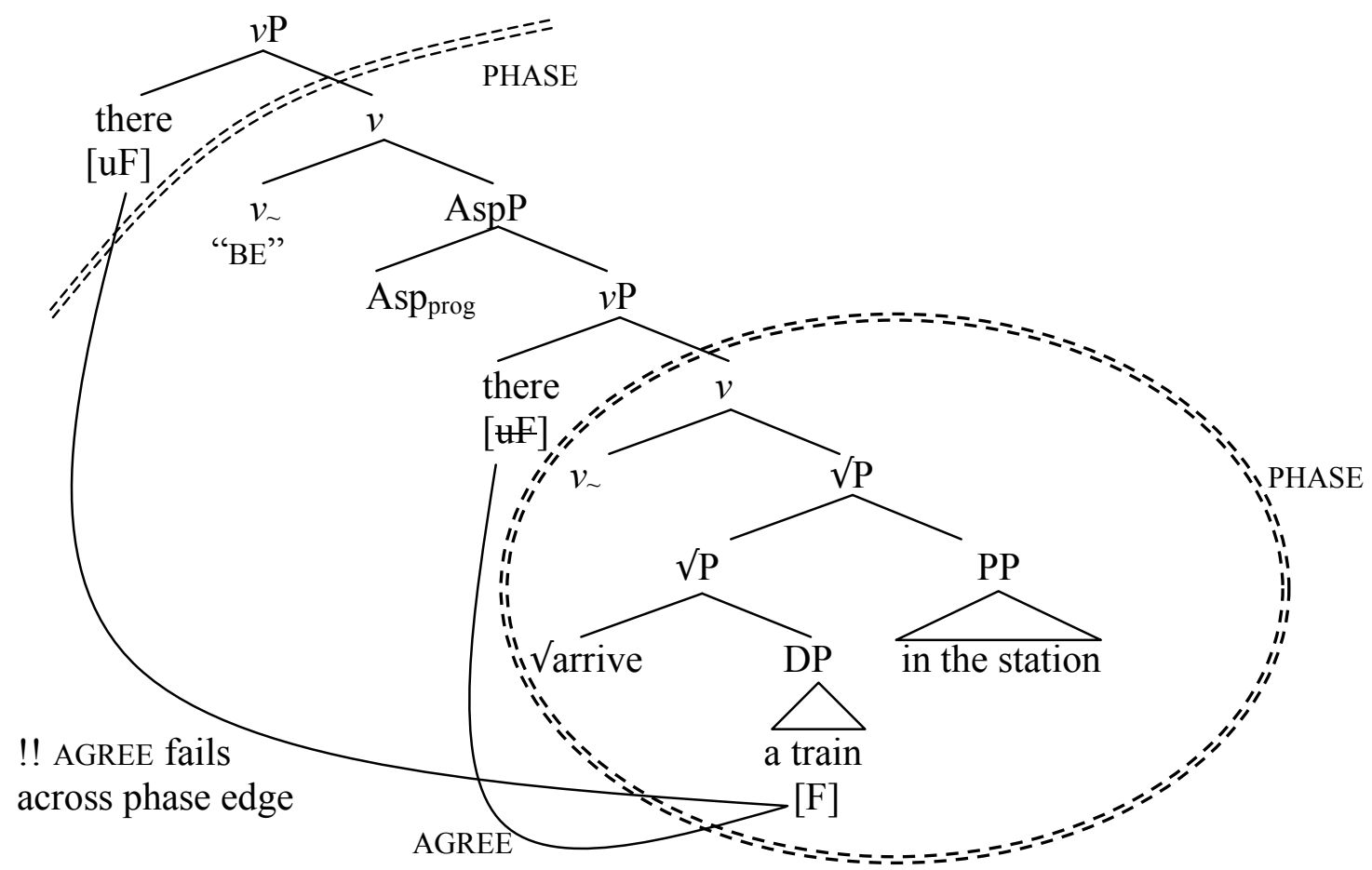

Thus, as a consequence of the structure of unaccusatives, there in There is a train arriving originates in the Spec, $v \mathrm{P}$ of arrive and not in the Spec, $v \mathrm{P}$ of the progressive $b e$.

\footnotetext{
${ }^{33}$ Note that tree (36) shows only the standard head-initial treatment of the English verbal projection; something more must be said to derive the final DP-Participle order in progressives like There is a train arriving or passives like There were four people arrested. Recent work on this topic has adopted the label $T h / E x$ for this word order pattern (and its crucial pre-participle NP position), following Chomsky (2001). See Caponigro and Schütze (2003), Rezac (2006).
} 
How, then, does the progressive allow there with unergative verbs? Given that the argument of an unergative is already projected in the specifier of the verbalizer Voice $v$, a locality problem does not ensue when there begins in the specifier of the higher $v$ head. Structure (37) exemplifies for There is a man laughing:

(37) Unergative: Agree is still local

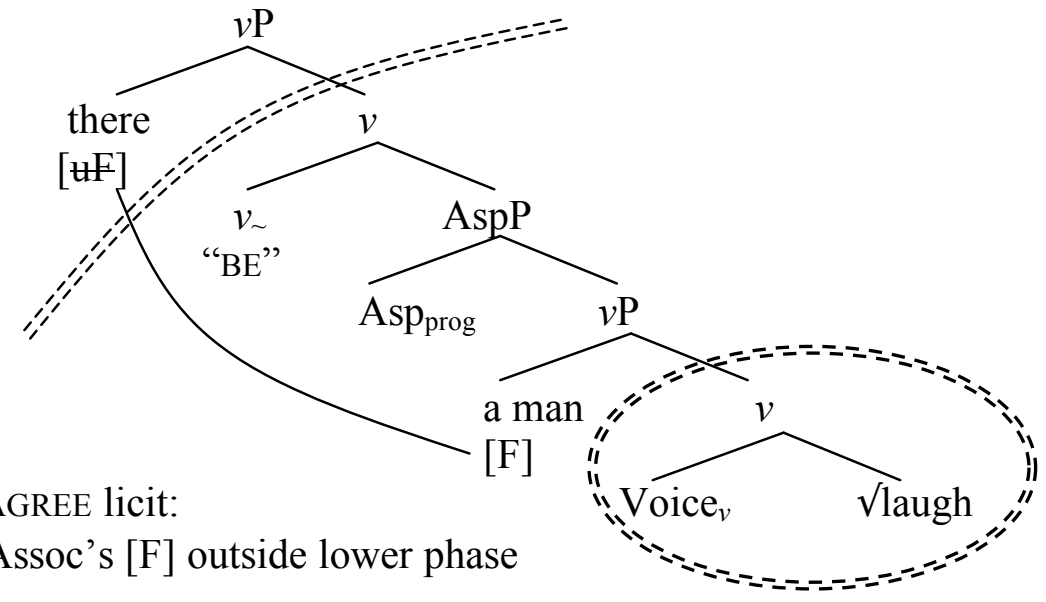

As (37) shows, the locality account allows us to generate there in the specifier of the progressive copula with unergative verbs while avoiding the too-many-theres problem with progressive unaccusatives. ${ }^{34}$

The second (and more famous) too-many-theres problem concerns raising verbs:

*There seemed there to arrive a train in the station.

(from 32b)

The locality account predicts that the trouble here stems from the higher there being too far away from the associate. There is indeed evidence that there in raising constructions must be generated downstairs: only when the embedded verb allows there, as in $(39 \mathrm{c}, \mathrm{d})$, may there appear as subject of seem. ${ }^{35}$

(39)a. *There seemed to disappear a dagger from the armory.

b. *There seemed to melt a lot of snow on the streets of Chicago.

c. There seemed to appear a dagger in front of Macbeth.

d. There seemed to arrive a train on track 3 .

If there could just be generated in the specifier of the raising verb (as proposed by Bošković 2002, Boeckx and Grohmann 2007), this contrast remains unaccounted for. On

\footnotetext{
${ }^{34}$ Note that this account correctly predicts that "transitive expletives" should indeed be possible in English when it is the copula that permits generation of the expletive, as in (i).

(i) There is a man eating an apple.

So far as I am aware, these constructions are the only transitive expletive constructions in English apart from those found with a small set of verbs whose objects are essentially locative, e.g. enter, reach, cross, hit.

(ii) There crossed her mind a most horrible thought. (Kuno and Takami 2004: 49)

(iii) Suddenly there entered the hall an ugly old man. (Levin 1993: 90)

I leave the proper analysis of this latter set of examples for future research.

${ }^{35}$ Thanks to Rajesh Bhatt for bringing this pattern to my attention.
} 
the other hand, the locality approach makes perfect sense of it. The phase geometry of (38) is exactly as in (36): the higher there is simply too many phases away from the associate it must agree with.

(40) Why high generation of there fails with raising verbs

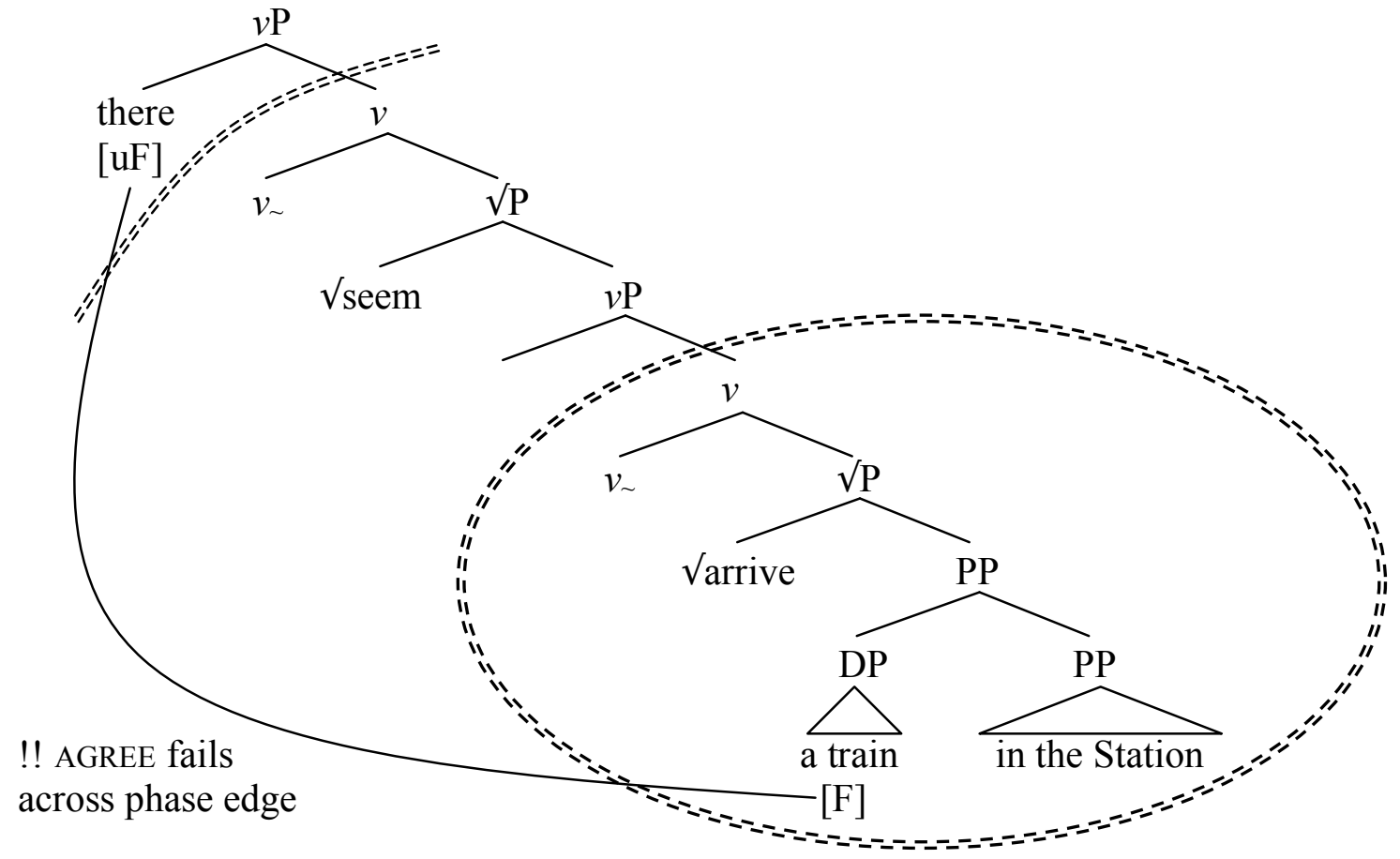

Confirmation for this analysis comes from cases where normal raising predicates such as seem or be likely embed nominals. In this case, the specifier of seem or be likely is not too far away from the nominal associate, and we find that these predicates can indeed license there-insertion:

(41)a. There is likely an error in line 3.

b. There seemed nothing we could do for poor Kim.

These facts show quite clearly that the too-many-theres problem with raising verbs arises not because raising verbs do not license there, but because there must attain a local relationship with its associate. By building in such a relation, we have been able to solve both versions of the too-many-theres problem and explain why there with raising verbs must be generated downstairs (if there is a downstairs). ${ }^{36}$ The phase-based approach also allows us to justify and broaden the generalization that there is inserted in Spec, $v \mathrm{P}$ : there-

\footnotetext{
${ }^{36}$ The phase-based approach also compares favorably an alternative locality approach based on the Minimal Link Condition (Chomsky 1995). On this approach, too-many-theres clauses would be ruled out by the lower there interfering in the relationship between the higher there and the associate. However, an MLC-based approach fails to predict that cases like $(39 \mathrm{a}, \mathrm{b})$ should be ungrammatical; given that the higher there is inserted into a non-thematic Spec, $v \mathrm{P}$ and that there is no lower there, the example is wrongly predicted to be grammatical. The phase-based approach explains why raising verbs must raise there; an MLC approach does not correctly make this prediction.
} 
insertion targets phasal specifiers which are not otherwise occupied by externally merged (i.e. thematic) elements. ${ }^{37}$ Thus, there-insertion allows otherwise illicit feature transmission via Agree across a phase boundary.

\subsection{Merge and Move}

A final point on raising verbs, agreement and locality concerns the possible associates that there can agree with. Importantly, the associate of there cannot be a lower there:

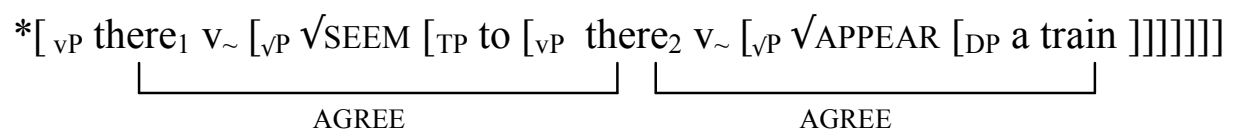

It is possible for an expletive merged in the lower Spec, $v \mathrm{P}$ position (in (42) occupied by there $_{2}$ ) to agree with the associate and then raise; it is not possible for there $e_{2}$ to agree with the associate, sharing its features, and then to agree qua associate with there ${ }_{1}$, further passing on those features. In other words, the expletive in the lower clause can be a link in a chain formed by movement, but it cannot be a link in a chain formed by merge of independent elements. I suggest that what we are seeing here is a familiar preference for chains to be formed by movement, not merger of independent elements. We see independently that both A and A' chains are formed by movement whenever possible, with resumption only as a last resort; if Merge were simpler than Move (as famously suggested by Chomsky 1995; for critical discussion, see Castillo et al. 1999, Richards 1999, Shima 2000), we might expect chains of resumptive elements to be quite widespread in natural languages. Expletive constructions, then, are only one piece of evidence that economy constraints on derivations actually favor movement (work fewer resources harder) over merger (spend, spend, spend!).

In this connection, of course, something must be said about those cases that originally motivated the Merge over Move constraint. The empirical fact is a curious one: when a raising verb embeds a TP, high there-insertion is disallowed even if the associate raises within the lower clause. Movement of the associate fails to feed local agreement with there. Accordingly, (43) is barred.

*There is likely a train to arrive in the station.

Given that there is local to its associate in this nevertheless ill-formed example, I suggest that the problem in such cases does not concern the there-associate link, but the position to which the associate has moved (as also claimed by Bošković 2002, Boeckx and Grohmann 2007). What is it about the non-finite Spec,TP position in a clause like (43) that could prohibit the associate from moving there? Perhaps it is that this position is not one in which nominals can be semantically interpreted. This helps us understand the paradigm of verbs Postal $(1974,1993)$ calls the "derived object control" (DOC) class:

(44)a. Stolen documents were alleged to be in the drawer.

$\checkmark$ PASSIVE OF ECM

\footnotetext{
${ }^{37}$ A similar view is advanced by Richards and Biberauer (2005) and Richards (2007), which came to my attention just prior to publication. Richards and Biberauer justify a phase-theoretic approach on largely theory-internal grounds and do not use it to constrain agreement relations.
} 
b. *John alleged stolen documents to be in the drawer. *ACTIVE ECM OF NP

c. John alleged there to be stolen documents in the drawer. $\checkmark$ ECM OF EXPLETIVE

Based on this DOC paradigm, Moulton (2007) observes that the Spec, TP position of noncontrol infinitives is a "lethal A-position", semantically speaking. Terms can only move to such a position if they are prepared to be interpreted elsewhere.

Given the independent evidence that the lower Spec,TP position in (43) is semantically lethal, the problem in (43) is spurious movement. The associate DP has moved, but its movement is semantically nullified by the lethal A-position, which will mandate reconstruction. That there is something wrong with A-movement that stands no chance of making a difference semantically is also seen in (44b); it seems that if stolen documents is going to be strong-armed into reconstructing in its post-copular position, it cannot raise to Spec, TP at all. The only way it can get its syntactic features to that position, if semantic interpretation is impossible there, is by sending an expletive proxy in its place, (44c). This is plausibly what happens in there-constructions with raising verbs as well. If anything at all is to pass through the lower Spec, TP in There is likely to arrive a train in the station, it will have to be there, which piggybacks on its associate semantically. Alternatively, given that Spec,TP is ex hypothesi not a phase edge, it may be that nothing need pass through this position at all, as suggested by Bošković (2002) and Boeckx and Grohmann (2007).

\section{$7 \quad$ Does there bear Case?}

At the outset of the previous section, we saw that the too-many-theres problem would require abandoning either the view that there does not have Case or the view that there is no relationship between there and its associate. The second of these approaches, adopted here, has led to a number of empirical successes. Crucially, not only have we solved the too-many-theres problem, we have done so in a way that explains why there must be generated downstairs with raising verbs, even though such verbs are independently capable of introducing there. Although we could alternatively solve the too-many-theres problem by stipulating that there must bear Case (i.a. Lasnik 1995), the facts from raising verbs do not follow from Case alone. Therefore, considerations about the Case-marking of there must be argued independently from the matters of locality discussed above.

That said, it is entirely possible that the feature $\mathrm{F}$ in which there and its associate agree is a Case feature, or that the two share all features including Case and $\phi .{ }^{38}$ Assuming some version of Case-sharing allows us to account for the paradigm noted by Lumsden (1988: 44) for case-marking on $w h$-words. An associate $w h$-extracted from a matrix thereclause can only be nominative:

*Whom was there in the house?

\footnotetext{
${ }^{38}$ For discussion see Safir 1982, Chomsky 1986b, den Dikken 1995, Emonds 2000: §5.5.2, Hale and Keyser 2000, Hazout 2004.
} 
This contrasts crucially with a case where accusative is expected to be transmitted to the associate, via there, in an ECM construction: ${ }^{39}$

\section{Whom/who did Bill expect there to be in the house?}

Assuming that there and its associate agree in Case $/ \phi$ also allows an important conceptual advantage: it allows us to establish a single unit of locality (viz the phase) over which all agreement relations are stated, including the relation between a Case-marker and a Case-marked item and the relationship between there and its associate. Let us see concretely how this might be accomplished. Supposing that both Case and $\phi$ are at stake, we can take there as entering a derivation with $u$ (nvalued )Case and $u$ (nvalued ) $\phi$ features. Its $u \phi$ features act as a probe and Agree with the associate DP, unifying the u $\phi$ and uCase features of the associate with those of there. (In order for two elements to agree in a feature without valuing it, we will need to employ a distinction between valuation and interpretation along the lines of Pesetsky and Torrego 2004. I assume this distinction here.) Subsequently, u $\phi$ and Case on $\mathrm{T}^{0}$ probe there, Agree with it, and remerge it as specifier of $\mathrm{T}^{40}$ A monoclausal example like There appeared a train will be derived as follows:

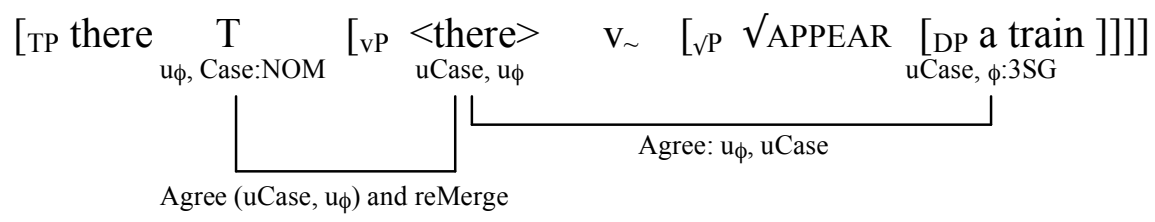

Note that in this example and in any extension of it where there moves successivecyclically between its base position and Spec,TP, no Agree relation will be required to cross more than one phase boundary. (In multiclausal examples we will need to motivate intermediate steps in successive movement; this is only part of the larger question of how

\footnotetext{
${ }^{39}$ Francez (2006) notes, however, that in matrix examples where case-marking is visible on a pronominal associate, it is in fact accusative, not nominative. This pattern is also attested in examples of Bolinger's.

(i) There were them and there was us.

(Francez 2006; also attested online)

(ii) If there were only him, you'd be denying the essential goodness of human nature. (Bolinger 1977:116) This accusative may be a default Case. Examples like these raise the question of whether nominative Case necessarily makes it to the associate in expletive constructions, suggesting that there may be variation in the degree to which $\phi /$ Case features are shared between expletive and associate; in clauses like there was us, neither person nor Case is transferred. Interestingly, (accusative) pronouns do not appear as associates of there with verbs other than the copula:

(iii) $\quad *$ There arrived us/them.

This may be related to the observation that verbs other than the copula do not allow singular agreement with a plural subject (Rochemont 1978:37, Schütze 1999):

(iv) So say there're/'s two problems.

(v) So say there arise/*arises two problems.

${ }^{40}$ This form of "proxy" analysis of there for both Case and agreement finds a direct antecedent in Chomsky (1986b,§3.3.3.3.1): "The verb of the main clause agrees with its subject there, which in turn agrees with the [associate] to which it is linked". In keeping with technology available at the time, Chomsky went on to propose a movement-based "expletive replacement" analysis (Chomsky 1986b:179, 1991, 1993, 1995); see den Dikken (1995), Runner (1995: ch 8), Sabel (2000) and others for critique. See also Hoekstra and Mulder (1990: 38) for an alternative proxy analysis.
} 
successive cyclic movement is linked to or motivated by feature checking, which I leave as an open question here.)

The approach to contrast with the analysis in (47) goes as follows (following Chomsky 1995, 2000; see Hazout 2004 for additional critique). If we were to assume that there does not bear Case and/or $\phi$ and that the associate checks its Case/ $\phi$ directly against finite $\mathrm{T}$, then the Case/ $\phi$-checking relationship between $\mathrm{T}$ and the associate will violate phase locality in multiclausal there-constructions. In (48), the relationship between $\mathrm{T}$ and the associate (shown by the dashed line) crosses multiple "weak" phases, even though we have seen that the there-associate relationship cannot cross phase boundaries in this way.

(48) A locality gap

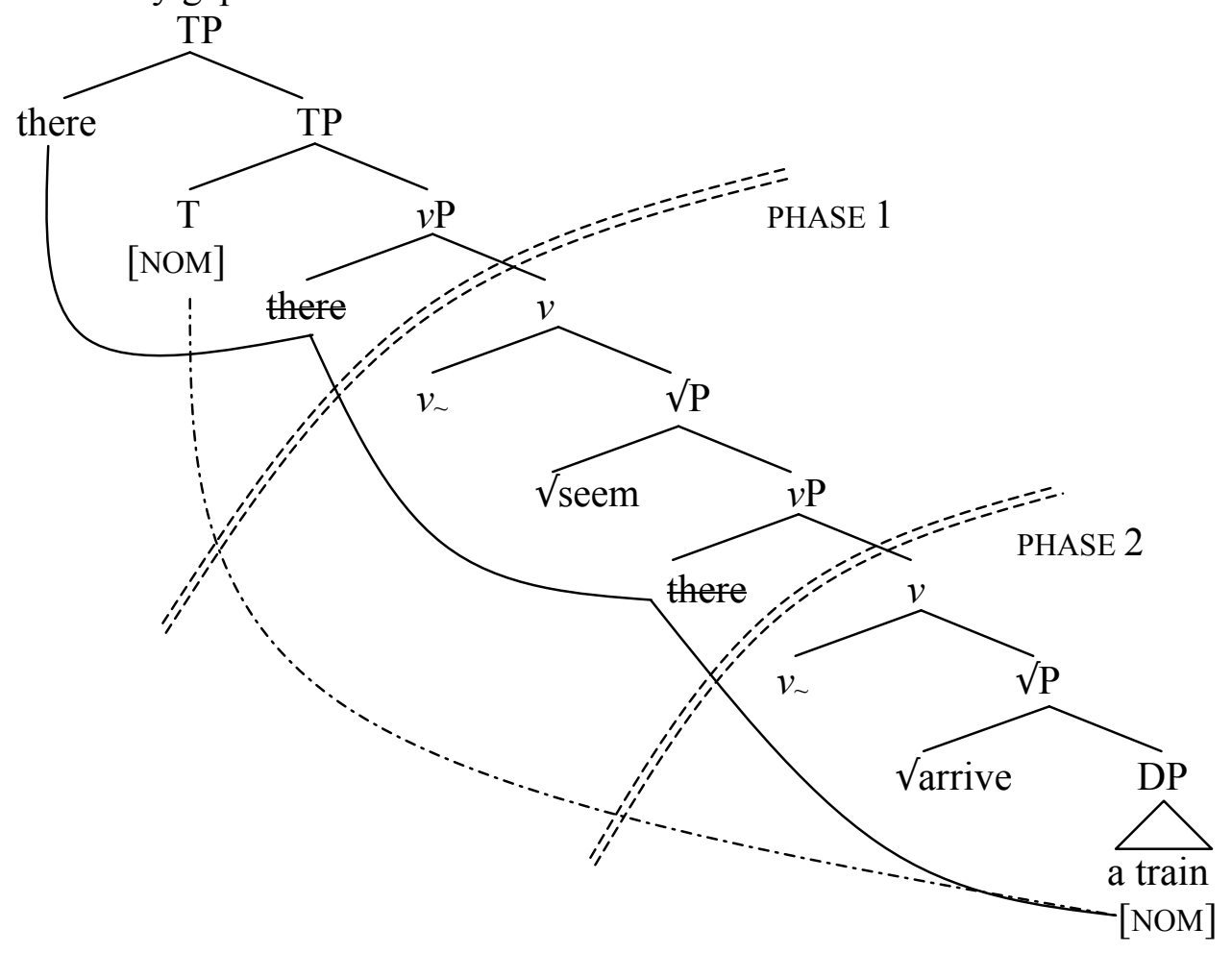

The agreement relations shown in (48) require an apparently ad hoc distinction between those which must respect all phases, e.g. the relationship between there and its associate, and those which can seemingly ignore "weak" phases at will, as in the case of the T-DP relationship. Yet if, as suggested above, there first agrees in Case $/ \phi$ with its associate, and then is the target of Case assignment for its associate, the domains for Case-assignment and there-associate Agreement are the same. Both must be local to every $v \mathrm{P}$, effectively obviating the need for a distinction between strong and weak phases, pace Chomsky (2001).

\section{$8 \quad$ Why is there there?}

A final concern to address in the study of there is the difficult question of why expletives like there should exist in natural languages, especially given that economy considerations 
disfavor them. In this connection I want to suggest, as many have before, that the purpose of there-insertion is not entirely separate from the definiteness restriction that famously (sometimes) constrains it. There-insertion allows an indefinite argument to remain in an object position in the scope of VP-level existential closure (Diesing 1992, Groat 1995: fn 7). This advantage is lost on definite arguments, which are not subject to existential closure. However, as the definiteness restriction has been repeatedly proven less than absolutely universal (Milsark 1974, Bolinger 1977, Rando and Napoli 1978, Woisetschlaeger 1983, Lumsden 1988, Enç 1991, Ward and Birner 1995, 1996, McNally 1997), the entire explanation for there-insertion cannot be found here. I suggest that most generally, there is a means for circumventing the EPP requirement that otherwise forces English subjects to appear high and towards the beginning of the clause. This comes at the insistence of interface constraints connecting syntax to interpretation and to information structure; there-insertion allows indefinite subjects to remain structurally low, providing an unambiguously weak interpretation (and yielding a definiteness effect), and allows novel material to appear toward the end of the clause, in alignment with information-structural organization.

Beginning with cases that obey the definiteness effect, it has been noted by Enç (1991) and others that there-insertion associates are necessarily non-specific; non-specific nominals must be interpreted within VP, the domain of existential closure (Diesing 1992). ${ }^{41}{ }^{42}$ Movement of a non-specific nominal out of VP is only possible if the movement is semantically undone by reconstruction (interpretation of a lower copy). In this case it will be ambiguous whether the nominal is to be interpreted specifically or not. Given this, we might note that there-insertion seems to be the only way of producing unambiguously non-specific interpretations of subjects in English. (There are not, for instance, antonyms of a certain $N$ that unambiguously reveal a semantically non-specific denotation. Even an arbitrary $N$ has a specific reading; it is just not clear which specific object is being referenced.) Thus, forming a chain via merger of there gives an otherwise impossible unambiguous LF for a non-specific, VP internal associate. ${ }^{43}$

Several classes of there-insertion have been identified that do not obey the definiteness restriction, however: listing or enumerative uses, and what have been called outside verbals, as in (49). These latter cases are clauses where the associate occurs to the right of VP (where VP is a cover term for various projections that may fall below $v \mathrm{P}$ in a verbal structure, including $\sqrt{\mathrm{P}}$ and any projections required to accommodate modifiers).

(49) Suddenly there [vp flew [pp through the window] ] [DP that shoe on the table ] (Milsark 1974: 246)

Outside verbals require an associate that is both discourse-novel and prosodically heavy (Bolinger 1977, Ward and Birner 1996, McNally 1997). The newness condition is revealed

\footnotetext{
${ }^{41}$ If we adopt a property-type or predicative denotation for weak or non-specific nominals (see Zimmermann 1992, van Geenhoven 1998, Dayal 2003, Chung and Ladusaw 2004), our semantics can dovetail with syntactic claims that the associate is a predicate (i.a. Williams 1994, Hazout 2004, Francez 2006).

${ }^{42}$ In terms of the structures adopted here, I assume Diesing's VP may be taken to be vP. I retain her terminology temporarily for clarity.

${ }^{43}$ Forming a chain with two theres gives no such interpretive advantage, however.
} 
by cases like (50) from Ward and Birner, where an otherwise acceptable outside verbal there-sentence is ruled out by a context in which the associate is not novel:

(50) President Clinton appeared at the podium accompanied by three senators and the Vice President. \#There stood behind him the Vice President.

The heaviness condition is shown in cases like the following, from Bolinger (1977: 117):

$$
\text { Behold! There stands before you *Christ/ the Son of God! }
$$

Outside verbals are characteristically diagnosed by (and have been named for) the presence of one or more constituents between the verb and the associate, e.g. through the window in (49). Here, however, I will use the term simply to refer to cases where the associate appears to the right of VP. This will be most easily visible in cases where VP-internal material intervenes between verb and associate, but is not restricted to such cases. ${ }^{44}$

(52) Towards the party of tourists there [XP [ $\mathrm{vP}$ Swam] [DP a man in a wetsuit carrying a harpoon ] ]

The outside verbals are revealing as to the etiology of there-insertion as they show an interesting cluster of differences from inside verbals (where the associate remains in its base position $v \mathrm{P}$-internally) and copular there-sentences: unlike these more famous cases, outside verbals have no definiteness restriction or quantificational restriction, and in contrast to the stringent restrictions on the verbs that allow there-insertion as inside verbals, outside verbals allow "a bewildering variety of verbs" (Milsark 1974: 247). This includes both unergative verbs, (53), and verbs of change of state, (54):

(53)a. Late at night, there crept into the small mountain village a silent band of soldiers. (Kuno and Takami 2004: 41)

b. Then there danced towards us a couple dressed like Napoleon and Josephine. (Kuno and Takami 2004: 35)

(54)a. I was stationed at a window looking down upon them, when suddenly there opened on the opposite side of the quadrangle a folding door, with glass panels, that leads into a balcony. 45

b. Ronald Reagan had a neat, three-sided diagram of the future in his first election: to reduce inflation, re-establish U.S. defense and balance the budget. But the triangle would not join, and through the gap in its apex, there ballooned a budget deficit of terrifying dimensions. ${ }^{46}$

\footnotetext{
${ }^{44}$ Cf. Kuno and Takami (2004: 45), from which the example is drawn. These authors analyze this and similar cases as inside verbals due to the absence of an XP between swim and a man.

${ }^{45}$ From 'The Castle of Scharfenstein', The Novelist's Magazine, 1833, p. 559. Despite the intervening years the example remains grammatical for present speakers.

${ }^{46}$ From 'The shaping of the presidency 1984', Time, Nov. 19, 1984.
} 
The position of the associate to the right of modifier PPs suggests that the associate is outside VP in the outside verbals. For unaccusative subjects, originating as sister to the verb root, this position may be derived either via right adjunction to $\mathrm{VP}$ or $v \mathrm{P}$, along the lines suggested by Guéron (1980), Lumsden (1988), Kuno and Takami (2004) and others, or by associate movement to the edge of $v \mathrm{P}$ plus (remnant) movement of the $\mathrm{VP}^{47} \mathrm{On}$ either analysis, the associate may be taken to have left the $v \mathrm{P}$ phase and entered the next, higher phase. For unergative subjects, taken to originate on the edge of the $v \mathrm{P}$ phase, similar proposals may be considered. For concreteness, I adopt here the VP-fronting analysis for both types of verbs. ${ }^{48}$

We have seen above that there originates on the edge of the $v \mathrm{P}$ phase in inside verbals in order to agree locally with its $v \mathrm{P}$-internal associate, ferrying the associate's features across a phase edge. In the outside verbals, however, the associate is already external to $v \mathrm{P}$. There-insertion on the edge of the (lowest) $v \mathrm{P}$ is not needed to move the associate's features to a higher phase. Therefore, the lowest $v \mathrm{P}$ is not the locus of thereinsertion in outside verbals; accordingly, those aspects of $v \mathrm{P}$ structure that inveigh against there-insertion with inchoative and agentive $v \mathrm{Ps}$ in inside verbals are nullified in the derivation of outside verbals.

Where, then, is there merged in the derivation of outside verbals? It cannot be Spec,TP: this position is not on a phase edge, and moreover, cannot be filled directly by there even when its associate is outside the $v \mathrm{P}$ phase (e.g. as the subject of an unergative verb):

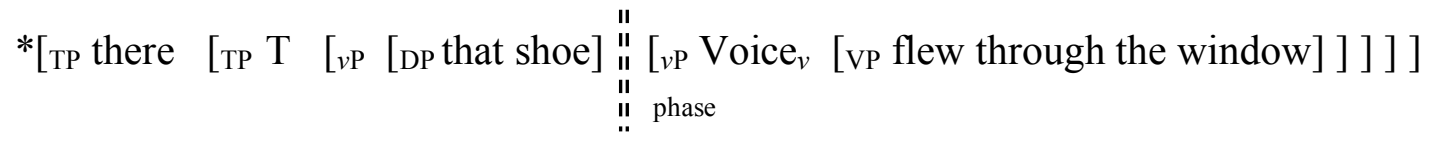

The crucial difference between this ungrammatical example and grammatical cases of outside verbal there-insertion with unergative verbs is that VP fronting has not occurred here. This recalls the previous case where we noted there-insertion with unergative verbs: the progressive, which we analyzed as accompanied by a $v_{\sim}$ verbalizer creating a phase boundary on whose edge there could be generated. I suggest a similar analysis here: thereinsertion is made possible by the generation of an intermediate phase between the associate and $\mathrm{T}$. This phasal projection provides a landing site for VP fronting, and as no other element need be externally merged on its edge, there may originate there. VP-movement has the effect of placing the associate sentence-finally, in a position favored for novel information by interface constraints regarding information structure. In this position the associate is independent of VP prosodically, which may explain the weight restriction. What is the syntactic and semantic identity of the phase head that sets off this chain of events? I speculate that it is associated with givenness, and will call it G, perhaps suggestively. Example (49) has the structure in (56): ${ }^{49}$

\footnotetext{
${ }^{47}$ This analysis is inspired by Larson's (1988) suggestion that "“heavy NP shift' is in reality a case of 'light predicate raising"' (p. 347).

${ }^{48}$ Facts from NPI licensing favor the VP fronting analysis. Right extraposition places the subject in a position from which it continues to c-command into VP, and so is expected to be able to license NPIs there. This prediction is falsified:

(i) *There walked into any classroom no one from my department.

${ }^{49}$ I have omitted for simplicity the trace of cyclic movement of VP through the specifier of the lower $v$ P.
} 


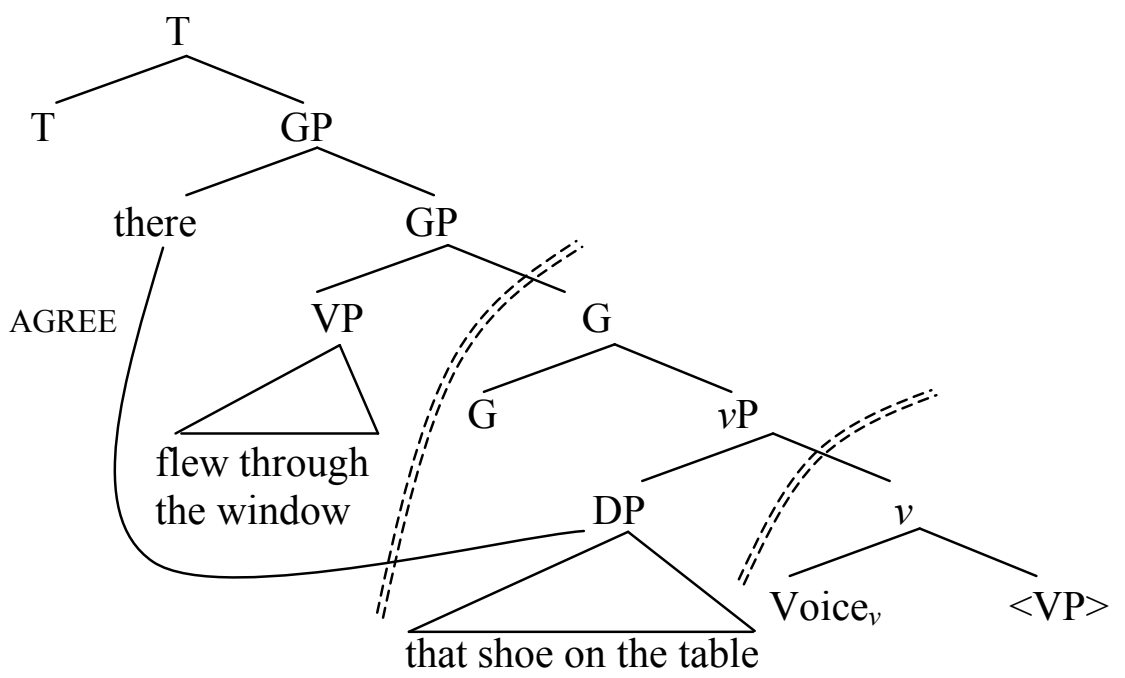

A similar, VP-fronting analysis may be adopted for locative inversion, which seems to make use of the same class of verbs as the outside verbals (Levin and Rappaport Hovav 1995: 220). The preposed PP is (comparatively) discourse-old (Ward and Birner 1996) and may be taken to occupy a Topic position in the left periphery. With the PP extracted, the fronted VP is no longer necessarily prosodically independent, and therefore locative inversion lacks the requirement that the associate be heavy (though it shares with thereinsertion a requirement that the associate be (comparatively) discourse-new).

Through the window flew John.

(cf. *There flew through the window John)

Levin and Rappaport Hovav (1995: ch 6) argue that locative inversion requires a verb that is "informationally light" so as not to "detract from the newness of the information conveyed by the postverbal NP" (p. 230). This requirement seems to be shared by outside verbal there-insertion and may be analyzed in terms of a givenness requirement on the fronted VP, though I leave the full analysis for future research.

We may conclude from our investigation of the wider range of there-sentences that there is essentially an agreement mediator in both inside verbal and outside verbal theresentences. We see that it can indeed ferry the associate's features to a higher Spec, TP in an outside verbal, via raising:

(58)a. There is believed to have sat next to Mary a stranger (Rochemont 1978: 55)

b. In these momentary vistas there seem to open before me bewildering avenues to all the wonders \& lovelinesses I have ever sought. ${ }^{50}$

c. There seemed to vanish from his mind any recollection that he had ever held any opinion other than the approved one. ${ }^{51}$

These examples suggest that the role of there-insertion in both inside and outside verbal constructions is to allow the associate's grammatical features to migrate to a high position

\footnotetext{
${ }^{50}$ H.P. Lovecraft, quoted at http://theteemingbrain.wordpress.com/category/quotations/

${ }^{51} \mathrm{http}: / /$ www.snyders.ws/alan/quotes/chambers.htm
} 
in the structure while allowing the associate itself to remain low. In terms of Case and agreement, the expletive is a proxy for its associate. Having such a proxy structure allows the associate nominal to divorce its grammatical position from its discourse status, receiving all the grammatical benefits of subject position (Case, agreement, \&c) without adopting the information-structural and syntactic commitments of actually surfacing there.

\section{Conclusion}

This paper has been concerned with two properties of the expletive there. Based on evidence from apparent "selection", I have argued that there must be generated low. In an inside verbal, the presence of a thematic element in Spec, $\nu \mathrm{P}$ preempts there; this includes both the nominal argument of a Voice head and the eventive argument of a CAUSE head. This suggests that there must be generated in the specifier of a verbalizer head $v$ which is not occupied by some thematic element. In the inside verbals, this is the lowest Spec, $v \mathrm{P}$. I have argued that this position is targeted because it is a phase edge. Higher functional structure may introduce additional phase edges which may also house there, enabling there-insertion with all sorts of verbs in the progressive and an intermediate range of verbs in the outside verbal construction. The wider range of verbs allowed in the former configuration may be due to the necessary backgrounding of the VP in the outside verbals.

The core locality fact explored here, that there is merged in the Spec, $v \mathrm{P}$ position because it must agree with its associate in a local fashion, moves us toward an understanding of the content of the expletive. There contains features which agree with those of its associate. The driving force behind there-insertion is the fact that there is an agreer, not the fact that it is devoid of descriptive semantic content (as enshrined in the Extended Projection Principle of Chomsky 1981). If we can identify the features in which there and its associate agree as including a Case feature, we attain the desirable result that all agreement relations may be stated over the same domains, i.e. phases; we dispense with any need to partition phases into "strong" and "weak" categories.

The conception of there as a Case/agreement "ferry" has also allowed us to explore the reasons that expletives like there exist in natural language. We have seen that the agreement that there enters into allows its associate to remain low in the structure while at the same time sharing Case and agreement features with the $v \mathrm{P}$-external subject position. This is advantageous either because the associate is a non-specific nominal which must undergo existential closure, or because it is novel to the discourse and optimally placed at the end of the clause. These two interface-driven considerations correspond to different syntactic solutions, the inside and outside verbal constructions, respectively. The findings overall suggest that English expletive constructions have much to offer for future research not merely on narrow syntax but also on the interfaces of the syntactic engine with semantic interpretation, information structural partitioning and what have been considered lexical aspects of the meanings of verbs. 


\section{References}

Abbott, B. 1995. Some remarks on specificity. Linguistic Inquiry 26:2, 341-347.

Aissen, J. 1975. Presentational there-insertion: a cyclic root transformation. Proceedings of CLS 11, 1-14.

Alexiadou, A. \& E. Anagnostopoulou. 2004. Voice morphology in the causativeinchoative alternation: evidence for a non-unified structrual analysis of unaccusatives. In The unaccusativity puzzle, eds. A. Alexiadou et al., pp. 114-136. Oxford: Oxford University Press.

Alexiadou, A., E. Anagnostopoulou \& F. Schäfer. 2006a. The properties of anticausatives cross-linguistically. In Phases of interpretation, ed. M. Frascarelli, pp. 187-211. Berlin: Mouton.

Alexiadou, A., E. Anagnostopoulou \& F. Schäfer. 2006b. The fine structure of (anti)causatives. In Proceedings of NELS 36, eds. C. Davis, A.R. Deal \& Y. Zabbal, pp. 115-128. Amherst, MA: GLSA.

Basilico, D. 1997. The topic is there. Studia Linguistica 51:3, 278-316.

Bobaljik, J.D. 2002. A-chains at the PF-interface: copies and 'covert' movement. Natural Language and Linguistic Theory 20, 197-267.

Bobaljik, J.D. \& D. Jonas. 1996. Subject position and the roles of TP. Linguistic Inquiry 27:2, 195-236.

Boeckx, C. \& K. Grohmann. 2007. Putting phases into perspective. Syntax 10:2, 204-222.

Bolinger, D. 1977. Meaning and form. London: Longman.

Bošković, Ž. 2002. Expletives don't move. In Proceedings of NELS 32, ed. M. Hirotani, pp. 21-40. Amherst, MA: GLSA.

Bowers, John. 2002. Transitivity. Linguistic Inquiry 33:2, 183-224.

Breckenridge, J. 1975. The post-cyclicity of es-insertion in German. Proceedings of CLS 11, 81-91.

Burzio, L. 1986. Italian syntax: a government-binding approach. Dordrecht: Reidel.

Caponigro, I. and C. Schütze. 2003. Parameterizing Passive Participle Movement. Linguistic Inquiry 34:2, 293-308.

Cardinaletti, A. 1997. Agreement and control in expletive constructions. Linguistic Inquiry 28:3, 521-533.

Castillo, J.C., J. Drury \& K. Grohmann. 1999. Merge over move and the extended projection principle. In University of Maryland Working Papers in Linguistics 8, eds. S. Aoshima et al., pp. 63-103.

Chierchia, G. 1989. A semantics for unaccusatives and its syntactic consequences. Ms., Cornell University. [Published 2004 in The unaccusativity puzzle, eds. A. Alexiadou et al. Oxford: Oxford University Press.]

Chomsky, N. 1981. Lectures on government and binding. Dordrecht: Foris.

Chomsky, N. 1986a. Barriers. Cambridge, MA: MIT Press.

Chomsky, N. 1986b. Knowledge of language: its nature, origin, and use. New York: Praeger.

Chomsky, N. 1991. Some notes on economy of derivation and representation. In Principles and parameters in comparative grammar, ed. R. Freidin, pp. 417-454. Cambridge, MA: MIT Press. 
Chomsky, N. 1993. A minimalist program for linguistic theory. In The view from building 20, eds. K. Hale and S.J. Keyser, pp. 1-52. Cambridge, MA: MIT Press.

Chomsky, N. 1995. The Minimalist program. Cambridge, MA: MIT Press.

Chomsky, N. 2000. Minimalist inquiries: The framework. In Step by step: Essays on minimalist syntax in honor of Howard Lasnik, eds. R. Martin, D. Michaels \& J. Uriagereka, pp. 89-155. Cambridge: MIT Press.

Chomsky, N. 2001. Derivation by phase. In Ken Hale: A life in language, ed. M. Kenstowicz, pp. 1-52. Cambridge, MA: MIT Press.

Chung, S. \& W. Ladusaw. 2004. Restriction and Saturation. Cambridge, MA: MIT Press.

Dayal, V. 2003. A semantics for pseudo-incorporation. Ms., Rutgers.

Demuth, K. 1990. Locatives, impersonals and expletives in Sesotho. The Linguistic Review 7: 233-249.

De Lancey, S. 1984. Notes on agentivity and causation. Studies in Language 8, 181-213.

Diesing, M. 1992. Indefinites. Cambridge, MA: MIT Press.

Dikken, M. den. 1995. Binding, expletives and levels. Linguistic Inquiry 26:2, 347-354.

Dowty, D. 1979. Word meaning and Montague grammar. Dordrecht: Riedel.

Emonds, J. 1970. Root and structure-preserving transformations. Ph.D. dissertation, MIT.

Emonds, J. 2000. Lexicon and grammar: the English syntacticon. Berlin: Mouton de Gruyter.

Frampton, J. \& S. Gutmann. 1999. Cyclic computation, a computationally efficient minimalist syntax. Syntax 2:1, 1-27.

Francez, I. 2006. Semantic structure and argument realization in (mostly Hebrew) existentials. In Proceedings of Israel Association for Theoretical Linguistics 22, ed. Y. Falk, online at $<$ http://atar.mscc.huji.ac.il/ english/IATL//22/>.

Freeze, R. 1992. Existentials and other locatives. Language 68, 553-595.

van Geenhoven, V. 1998. Semantic incorporation and indefinite descriptions. Stanford: CSLI.

Groat, E. 1995. English expletives: a minimalist approach. Linguistic Inquiry 26:2, 354365.

Guéron, J. 1980. On the syntax and semantics of PP extraposition. Linguistic Inquiry 11:4, 637-678.

Haegeman, L. 1991. Introduction to government and binding theory. Oxford: Blackwell.

Hale, K. \& S.J. Keyser. 2000. There-insertion unaccusatives. Ms., MIT.

Haiman, J. 1974. Targets and syntactic change. The Hague: Mouton.

Harley, H. 2007. External arguments: on the independence of Voice and v. Abstract for GLOW XXX, Tromsø.

Harley, H. \& R. Noyer. 2000. Formal versus encyclopedic properties of vocabulary: evidence from nominalizations. In The lexicon-encyclopedia interface, ed. B. Peeters, pp. 349-374. Oxford: Elsevier Press.

Hay, J., C. Kennedy \& B. Levin. 1999. Scalar structure underlies telicity in "degree achievements". In Proceedings of SALT IX, eds. T. Matthews and D. Strolovitch, pp. 127-144. Ithaca: CLC Publications.

Hazout, I. 2004. The syntax of existential constructions. Linguistic Inquiry 35, 393-430.

Henry, A. \& S. Cottell. 2007. A new approach to transitive expletives: evidence from Belfast English. English Language and Linguistics 11:2, 279-299. 
Hoekstra, T. \& R. Mulder. 1990. Unergatives as copular verbs; locational and existential predication. The Linguistic Review 7:1, 1-79.

Holmberg, A. \& U. Nikanne. 2002. Expletives, subjects and topics in Finnish. In P. Svenonius (ed.), pp. 71-105.

Jackendoff, R. 1976. Towards an explanatory semantic representation. Linguistic Inquiry 7:1, 89-150.

Jackendoff, R. 1983. Semantics and cognition. Cambridge, MA: MIT Press.

Jackendoff, R. 1996. The proper treatment of measuring out, telicity, and perhaps even quantification in English. Natural Language and Linguistic Theory 14:2, 305-354.

Kallulli, D. 2006. Unaccusatives with dative causers and experiencers: a unified account. In Datives and Other Cases: Between argument structure and event structure, eds. D. Hole, A. Meinunger and W. Abraham, pp. 271-301. Amsterdam: John Benjamins.

Koontz-Garboden, A. 2005. On the typology of state/change-of-state alternations. Yearbook of Morphology 2005, 83-117.

Koontz-Garboden, A. 2007. Aspectual coercion and the typology of change of state predicates. Journal of Linguistics 43, 115-152.

Koopman, H. \& D. Sportiche. 1991. The position of subjects. Lingua 85, 211-258.

Koster, J. \& J.-W. Zwart. 2000. Transitive expletive constructions and the object shift parameter. Linguistics in the Netherlands 17, 159-170.

Kratzer, A. 1989. An investigation of the lumps of thought. Linguistics and Philosophy 12, 607-653.

Kratzer, A. 1996. Severing the external argument from its verb. In Phrase structure and the lexicon, eds. J. Rooryck and L. Zaring, pp. 109-137. Dordrecht: Kluwer.

Kratzer, A. 2005. Building resultatives. In Event arguments: foundations and applications, eds. C. Maienborn \& A. Wöllstein, pp. 177-212. Tübingen: Max Niemeyer Verlag.

Kratzer, A. 2007. Situations in natural language semantics. In The Stanford Encyclopedia of Philosophy (Spring 2007 edition), ed. E. Zalta. <http:// plato.stanford.edu/entries/situations-semantics/>.

Kuno, S. \& K.-I. Takami. 2004. Functional constraints in grammar: on the unergativeunaccusative distinction. Amsterdam: John Benjamins.

Larson, R. 1988. On the double object construction. Linguistic Inquiry 19:3, 335-391.

Lasnik, H. 1992. Case and expletives: notes toward a parametric account. Linguistic Inquiry 23, 381-405.

Lasnik, H. 1995. Case and expletives revisited: On Greed and other human failings. Linguistic Inquiry 26, 615-633.

Law, P. 1999. On the passive existential construction. Studia Linguistica 53:3, 183-208.

Legate, J.A. 2002. Some interface properties of the phase. Linguistic Inquiry 34, 506-516.

Levin, B. 1993. English verb classes and alternations: a preliminary investigation. Chicago: University of Chicago Press.

Levin, B. \& M. Rappaport Hovav. 1995. Unaccusativity: at the syntax-lexical semantics interface. Cambridge, MA: MIT Press.

Levin, B. \& M. Rappaport Hovav. 2002. Change of state verbs: implications for theories of argument projection. Proceedings of BLS 28, 269-280.

Lewis, D. 1986. Philosophical Papers, Volume II. Oxford: Oxford University Press. 
Lumsden, M. 1988. Existential sentences: their structure and meaning. London: Croom Helm.

Maling, J. 1988. Variations on a theme: existential sentences in Swedish and Icelandic. McGill Working Papers in Linguistics, Special Issue on Comparative Germanic Syntax, 168-191.

Marantz, A. 1984. On the nature of grammatical relations. Cambridge, MA: MIT Press.

Marantz, A. 1997. No escape from syntax: don't try morphological analysis in the privacy of your own lexicon. In University of Pennsylvania Working Papers in Linguistics 4.2, eds. A. Dimitriadis et al., pp. 201-225.

McNally, L. 1997. A semantics for the English existential construction. New York: Garland.

Milsark, G. 1974. Existential sentences in English. Ph.D. dissertation, MIT.

Moro, A. 1997. The raising of predicates. Cambridge: Cambridge University Press.

Moulton, K. 2007. Revisiting Postal's DOC: Lethal A-positions. Talk at ECO5, UMass, March.

Nomura, M. 2004. Expletives move! In Proceedings of WECOL 2003, eds. B. Agbayani et al., pp. 207-220. Fresno, CA: Cal State University Fresno.

Parsons, T. 1990. Events in the semantics of English: a study in subatomic semantics. Cambridge, MA: MIT Press.

Pesetsky, D. 1995. Zero syntax. Cambridge, MA: MIT Press.

Pesetsky, D. \& E. Torrego. 2004. The syntax of valuation and the interpretability of features. Ms., MIT and UMass-Boston.

Piñón, C. 2001. A finer look at the causative-inchoative alternation. In Proceedings of Semantics and Linguistic Theory 11, eds. R. Hastings et al. Ithaca, NY: CLC Publications.

Platzack, C. 1983. Existential sentences in English, German, Icelandic and Swedish. In Papers from the 7th Scandinavian conference on linguistics, ed. F. Karlsson, pp. 80-100. Helsinki: University of Helsinki Dept. of General Linguistics.

Postal, P. 1974. On raising. One rule of English grammar and its theoretical implications. Cambridge, MA: MIT Press.

Postal, P. 1993. Some defective paradigms. Linguistic Inquiry 24: 347-364.

Pylkkänen, L. 2002. Introducing arguments. Ph.D. dissertation, MIT.

Rando, E. \& D.J. Napoli. 1978. Definites in there-sentences. Language 54:2, 300-313.

Reinhart, T. 2002. The theta system: an overview. Theoretical linguistics 28, 229-290.

Rezac, M. 2006. The interaction of Th/Ex and locative inversion. Linguistic Inquiry 37:4, 685-697.

Richards, M. 2007. On object shift, phases and transitive expletive constructions in Germanic. In Linguistic Variation Yearbook 6, eds. P. Pica et al., pp. 139-159. Amsterdam: John Benjamins.

Richards, M. and T. Biberauer. 2005. Explaining Expl. In The function of function words and functional categories, ed. M. den Dikken, pp. 115-153. Amsterdam: John Benjamins.

Richards, N. 1999. Dependency formation and directionality of tree construction. In Papers on syntax and morphology, MITWPL 34, eds. V. Lin et al., pp. 67-105. Cambridge, MA: MITWPL. 
Rochemont, M. 1978. A theory of stylistic rules in English. Ph.D. dissertation, University of Massachusetts Amherst.

Rothstein, S. 1995. Pleonastics and the interpretation of pronouns. Linguistic Inquiry 26:3, 499-529.

Runner, J. 1995. Noun phrase licensing and interpretation. Ph.D. dissertation, University of Massachusetts Amherst.

Sabel, J. 2000. Expletives as features. In Proceedings of WCCFL 19, eds. R. Billerey et al., pp. 411-424. Somerville, MA: Cascadilla Press.

Safir, K. 1982. Syntactic chains and the definiteness effect. Ph.D. dissertation, MIT.

Schaffer, J. 2007. The Metaphysics of Causation. In The Stanford Encyclopedia of Philosophy (Winter 2007 Edition), ed. E. Zalta. <http://plato.stanford.edu/archives/ win2007/entries/causation-metaphysics/>.

Schütze, C. 1999. English expletive constructions are not infected. Linguistic Inquiry 30:3, 467-484.

Sells, P. 2005. The peripherality of the Icelandic expletive. In Proceedings of the LFG05 Conference, University of Bergen, eds. M. Butt and T. Holloway King.

Shima, E. 2000. A preference for Move over Merge. Linguistic Inquiry 31, 375-385.

Sobin, N. 2004. Expletive constructions are not "lower right corner" movement constructions. Linguistic Inquiry 35:3, 503-508.

Solstad, T. 2006. Lexical pragmatics and unification: the semantics of German causal durch 'through'. Ms., University of Oslo; available from the Semantics Archive.

Stowell, T. 1978. What was there before there was there? In Papers from the Fourteenth Regional Meeting, Chicago Linguistic Society, eds. D. Farkas et al., pp. 458-471.

Svenonius, P., ed. 2002. Subjects, expletives and the EPP. Oxford: Oxford University Press.

Szabolcsi, A. 1986. From the definiteness effect to lexical integrity. In Topic, focus and configurationality. Papers from the 6th Groningen Grammar Talks, eds. W. Abraham and S. de Meij, pp. 321-348. Amsterdam: John Benjamins.

Taraldsen, K.T. 2002. The que/qui alternation and the distribution of expletives. In P. Svenonius (ed.), pp. 29-42.

Thráinsson, H. 1979. On complementation in Icelandic. New York: Garland.

Toribio, A.J. 1996. Dialectal variation in the licensing of null referential and expletive subjects. In Aspects of Romance linguistics: Selected Papers from the Linguistic Symposium on Romance Languages XXIV, eds. C. Parodi et al., pp. 409-432. Washington, DC: Georgetown University Press.

Travis, L. 1984. Parameters and effects of word order variation. Ph.D. dissertation, MIT.

Vangsnes, Ø.A. 2002. Icelandic expletive constructions and the distribution of subject types. In P. Svenonius (ed.), pp. 43-70.

Vikner, S. 1995. Verb movement and expletive subjects in the Germanic languages. New York: Oxford University Press.

Ward, G. \& B. Birner. 1995. Definiteness and the English existential. Language 71:4, 722742 .

Ward, G. \& B. Birner. 1996. On the discourse function of rightward movement in English. In Conceptual structure, discourse and language, ed. A. Goldberg, pp. 463-479. Stanford, CSLI.

Williams, E. 1994. Thematic structure in syntax. Cambridge, MA: MIT Press. 
Woisetschlaeger, E. 1983. On the question of definiteness in "an old man's book". Linguistic Inquiry 14:1, 137-154.

Wunderlich, D. 1997. Cause and the structure of verbs. Linguistic Inquiry 28:1, 27-68.

Zimmermann, T. 1992. On the proper treatment of opacity in certain verbs. Natural Language Semantics 1:2, 149-180.

Department of Linguistics

University of Massachusetts Amherst

226 South College

Amherst MA 01003

amyrose@linguist.umass.edu 